\title{
əThe Dependence of Internal Multidecadal Variability in the Southern Ocean on the Ocean Background Mean State
}

\author{
Liping Zhang, ${ }^{\mathrm{a}, \mathrm{b}}$ Thomas L. Delworth, ${ }^{\mathrm{a}}$ William Cooke,${ }^{\mathrm{a}, \mathrm{b}}$ Hugues Goosse, ${ }^{\mathrm{c}}$ Mitchell Bushuk,${ }^{\mathrm{a}, \mathrm{b}}$ \\ YUSHI MORIOKA, ${ }^{\mathrm{d}}$ AND XIAOSONG YANG $^{\mathrm{a}}$ \\ ${ }^{\text {a }}$ NOAA/Geophysical Fluid Dynamics Laboratory, Princeton, New Jersey \\ ${ }^{\mathrm{b}}$ University Corporation for Atmospheric Research, Boulder, Colorado \\ ${ }^{\mathrm{c}}$ Earth and Life Institute, Université de Louvain, Louvain-la-Neuve, Belgium \\ d Application Laboratory, VAiG, JAMSTEC, Yokohama, Japan
}

(Manuscript received 24 January 2020, in final form 8 October 2020)

\begin{abstract}
Previous studies have shown the existence of internal multidecadal variability in the Southern Ocean using multiple climate models. This variability, associated with deep ocean convection, can have significant climate impacts. In this work, we use sensitivity studies based on Geophysical Fluid Dynamics Laboratory (GFDL) models to investigate the linkage of this internal variability with the background ocean mean state. We find that mean ocean stratification in the subpolar region that is dominated by mean salinity influences whether this variability occurs, as well as its time scale. The weakening of background stratification favors the occurrence of deep convection. For background stratification states in which the low-frequency variability occurs, weaker ocean stratification corresponds to shorter periods of variability and vice versa. The amplitude of convection variability is largely determined by the amount of heat that can accumulate in the subsurface ocean during periods of the oscillation without deep convection. A larger accumulation of heat in the subsurface reservoir corresponds to a larger amplitude of variability. The subsurface heat buildup is a balance between advection that supplies heat to the reservoir and vertical mixing/convection that depletes it. Subsurface heat accumulation can be intensified both by an enhanced horizontal temperature advection by the Weddell Gyre and by an enhanced ocean stratification leading to reduced vertical mixing and surface heat loss. The paleoclimate records over Antarctica indicate that this multidecadal variability has very likely happened in past climates and that the period of this variability may shift with different climate background mean state.
\end{abstract}

KEYWORDS: Southern Ocean; Multidecadal variability; Oceanic variability

\section{Introduction}

Multidecadal to centennial variability in the Southern Ocean (SO) is difficult to detect and characterize due to limited in situ observations. Paleoclimate tree ring records over adjacent continents do show long time scale variations in the past hundreds of years (e.g., Cook et al. 2000; Le Quesne et al. 2009). These low-frequency variations are seen in multiple climate models, including the Kiel Climate Model (e.g., Martin et al. 2013; Latif et al. 2013), Geophysical Fluid Dynamics Laboratory (GFDL) CM2Mc, ESM2M, CM2.1, and SPEAR (described in section 2) models (e.g., Cabré et al. 2017; Seviour et al. 2016, 2017; Zhang et al. 2017a), respectively. Simulated SO multidecadal to centennial variability is primarily associated with the SO deep convection fluctuations (e.g., Martin et al. 2013; Zhang and Delworth 2016).

Previous studies have shown that SO multidecadal to centennial deep convection variations have broad impacts on the global climate. Cabré et al. (2017) demonstrated that SO convection variability affects the global heat and hydrological balance, as well as interhemispheric atmospheric and oceanic

¿ Denotes content that is immediately available upon publication as open access.

Corresponding author: Liping Zhang, liping.zhang@noaa.gov heat transports. Zanowski et al. (2015) and Zhang and Delworth (2016) suggested that SO convection results in changes in ocean circulation, with effects being seen on the Antarctic Bottom Water (AABW) cell, the Antarctic Intermediate Water, and the North Atlantic meridional overturning circulation (AMOC). Zhang et al. (2017a,b) illustrated that the presence of convection results in decadal-scale predictability of SO SST and its associated climate impacts. Zhang et al. (2019) further suggested that internal SO convection variability may drive the observed SST and sea ice trends during 1979-2015. The SO convection regions are also found to be critical in the SO response to ozone depletion (Seviour et al. 2016, 2017).

Despite of the importance of SO convection, climate models have very diverse representations of deep convection location, frequency, and intensity (e.g., Reintges et al. 2017; Heuzé et al. 2013). Open ocean deep convection occurs in the Weddell Sea in some models, while it occurs in the Ross Sea or other seas in other models. The frequency of deep convection occurrence varies model by model, ranging from decadal to centennial time scales. There is also no consensus on the mechanisms driving the SO deep convection variability. The preconditioning of deep convection is provided by either the deep ocean or the ocean surface. In some models the deep preconditioning process is dominant, in which the heat builds up in the subsurface ocean during nonconvective periods, gradually decreasing ocean stability and therefore driving convection from below (e.g., Welander 1982; Martin et al. 2013; Dufour et al. 2017). In contrast, critical to 
the surface preconditioning mechanism is the development of positive surface salinity anomalies that can increase the density in the surface layer and thereby induce convection from above. The positive salinity anomalies can arise from oceanic sources such as sea ice formation and brine rejection (e.g., Martinson et al. 1981; Motoi et al. 1987) or atmospheric sources such as surface freshwater changes (e.g., Marsland and Wolff 2001; Gordon et al. 2007).

Given the significant differences in SO convection and multidecadal variability characteristics among climate models, we attempt to investigate the potential causes underlying these differences. We find that the SO mean stratification state is critical for the frequency of SO low-frequency variability whether the stability perturbation is generated from the surface or deep oceans, while the amplitude of variability is largely determined by the magnitude of the subsurface heat reservoir. Several recent studies demonstrated that the ocean stratification determines whether the convection occurs (e.g., Kjellsson et al. 2015; Stössel et al. 2015; Dufour et al. 2017; de Lavergne et al. 2014). In addition to this convection occurrence, our work here further shows that the ocean mean stratification state is also important for the intensity and frequency of the variability if convection occurs and oscillates. By analyzing the results of simulation performed in the framework of models from phase 5 of the Coupled Model Intercomparison Project (CMIP5), Reintges et al. (2017) found that the convection period is correlated with the ocean stratification mean state. However, different models may have different sensitivities and thus they were not able to attribute with high confidence the period differences solely to differences in ocean stratification. Our study confirms their conclusion in terms of convection period through the design and execution of sensitivity experiments using GFDL models. We also investigate how the convection amplitude responds to the ocean stratification mean state change and show what physical processes underlie this response. The realism of this convection low-frequency variability is also discussed based on paleoclimate records over Antarctica.

\section{Models, methods, and datasets}

The model used in the present study is the SPEAR (Seamless System for Prediction and Earth System Research) model (Delworth et al.2020), a newly developed atmosphere and ocean fully coupled model at GFDL. We use the relatively coarseresolution model SPEAR_LO and SPEAR_AM2. The SPEAR_ LO model uses the AM4 atmosphere component (Zhao et al. 2018) and has an atmosphere/land resolution of approximately $100 \mathrm{~km}$. The ocean and sea ice components in SPEAR_LO are constructed from the new MOM6 code and SIS2 sea ice code (Adcroft et al. 2019), with a horizontal resolution of approximately $1^{\circ}$ in the subtropics and approximately $0.5^{\circ}$ at high latitudes. The meridional grid resolution is also refined to $0.3^{\circ}$ in the tropics. The ocean model has 75 hybrid layers in the vertical, with 2-m resolution near surface. The SPEAR_AM2 is an early prototype version of SPEAR model, in which the atmosphere component is from AM2 (Anderson et al. 2004) and the ocean and ice models are the same as SPEAR_LO. The horizontal resolution in the atmosphere/land components of SPEAR_AM2 is $200 \mathrm{~km}$, while that in SPEAR_LO is $100 \mathrm{~km}$. In short, the SPEAR_LO and SPEAR_AM2 models have different atmosphere and land components but the same ocean and sea ice model components. We use a 4000-yr control simulation of SPEAR_LO and a 3000-yr control simulation of SPEAR_AM2, with atmospheric composition fixed at preindustrial 1860 concentrations for SPEAR_AM2 and 1850 for SPEAR_LO.

The SO in the SPEAR_LO control simulation displays substantial multidecadal to centennial variability, a characteristic also seen in previous versions of GFDL models (e.g., Cabré et al. 2017; Seviour et al. 2016, 2017; Zhang and Delworth 2016). Figure 1a shows the annual mean time series of the Antarctic Bottom Water cell index in SPEAR_LO. The AABW cell index here is defined as the absolute value of the minimum in the global meridional overturning streamfunction south of $60^{\circ} \mathrm{S}$, using a streamfunction computed in density space. This index represents the strength of SO deep convection very well (e.g., Zhang and Delworth 2016). The long-term mean AABW cell is approximately $24 \mathrm{~Sv}\left(1 \mathrm{~Sv} \equiv 10^{6} \mathrm{~m}^{3} \mathrm{~s}^{-1}\right)$, which is within the observed estimates $(21 \pm 6 \mathrm{~Sv})$ (Ganachaud and Wunsch 2001). Multidecadal internal variability is clearly seen, with a period around 80 years (Fig. 1b). This variability is largely associated with deep convection fluctuations over the Ross Sea (not shown). Similar centennial deep convection variability also occurs in the SPEAR_AM2 model (not shown).

\section{a. Sea ice albedo perturbation experiments using the SPEAR_LO (mean state response)}

To investigate the linkages between the SO mean state and the SO internal low-frequency variability, we first perturb ocean stratification mean state from above by changing the snow-sea ice radiation balance. We artificially and abruptly increase the optical properties of bare sea ice, snow, and ponded ice in the deltaEddington solar radiation treatment (Briegleb 1992). Specifically, we modify the optical coefficients $\left(R_{\text {ice }}, R_{\text {snow }}\right.$, and $R_{\text {pond }}$; they are standard deviation parameters and have a range between -2 and 2 ) in the sea ice component from default 0 to 1.5 (positive albedo anomaly). Note that the presence of pronounced internal variability over the SO can mask the direct effect of sea ice anomaly on the ocean mean state, particularly during the first several years when the ocean initial condition may persist. To remove these initial condition interferences, we conduct ten ensemble member experiments, in which half of the simulations are initialized from a strong AABW cell state (red dots in Fig. 1a) and the other half are initialized from a weak AABW cell state (green dots). The integration with ice albedo perturbation lasts 40 years for each ensemble member. The response is taken as the difference between the ensemble mean of these 10 perturbation experiments and their corresponding control run. Here we name it Albedo ${ }^{+1.5}$ EN. The use of ensemble averaging reduces the amplitude of the internal variability, so that the ensemble mean response mainly reflects the forced signals (i.e., the response of the time-mean ocean stratification to the imposed forcing).

\section{b. Sea ice albedo perturbation experiments using the SPEAR_LO model (internal variability response)}

We then investigate the role of ocean stratification in the SO internal low-frequency variability. We conduct four additional 
(a) The AABW cell index in SPEAR_LO

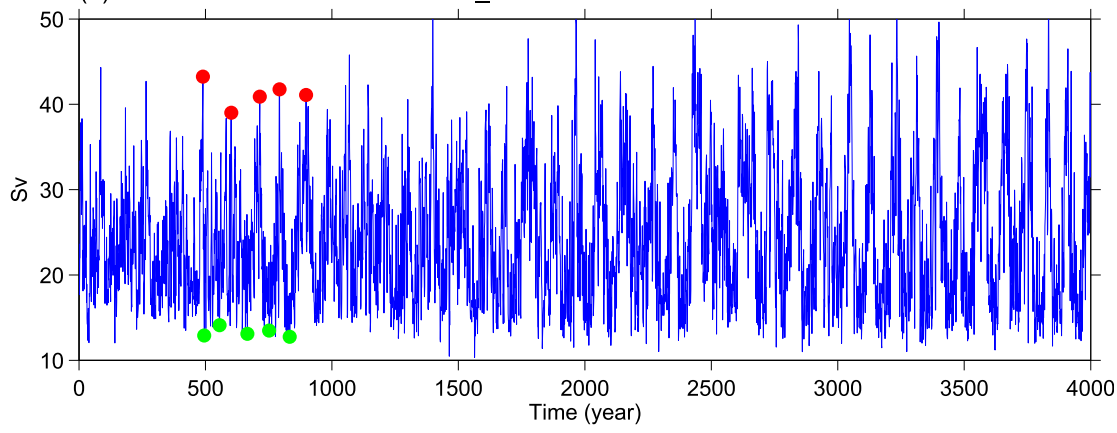

(b) Wavelet of the AABW cell index

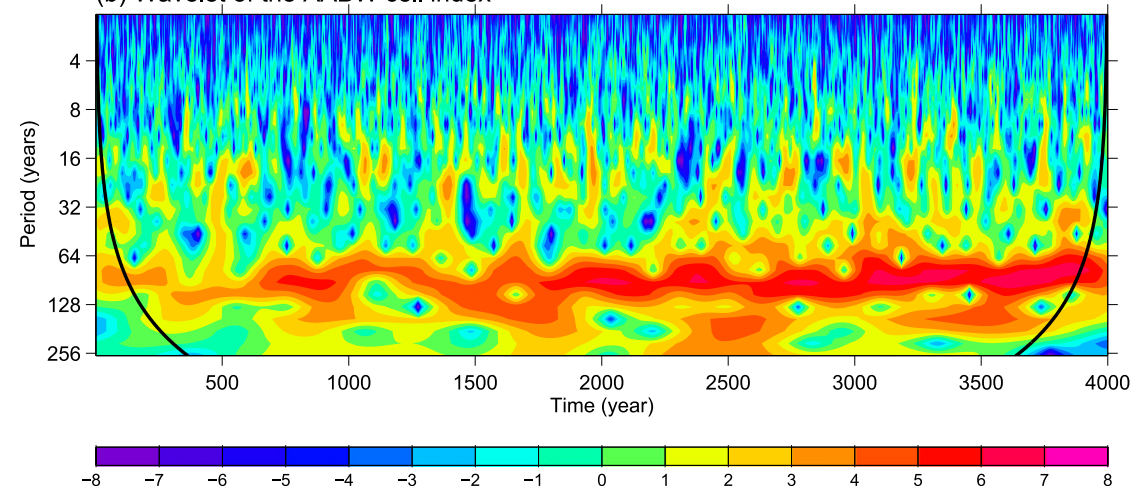

FIG. 1. (a) Annual mean time series of the Antarctic Bottom Water (AABW) cell index (Sv) in the SPEAR_LO model Control run. The red (green) dots show the starting years used to initialize the following sea ice albedo perturbation experiments that are characterized by strong (weak) convection state. (b) Wavelet analysis of the AABW cell index in 4000 years.

$600-\mathrm{yr}$ simulations to assess the response of the variability to the albedo perturbation. These perturbation experiments are initialized from the 500th year of control simulation and are continued for 600 years. We modify the optical coefficients ( $R_{\text {ice }}, R_{\text {snow }}$, and $\left.R_{\text {pond }}\right)$ in the sea ice component from default 0 to $+1.5,+0.5,-0.5$, and -1.5 , respectively. All three optical coefficients ( $R_{\text {ice }}, R_{\text {snow }}$, and $R_{\text {pond }}$ ) have the same values and are changed together. We name these experiments Albedo ${ }^{+1.5}$, Albedo $^{+0.5}$, Albedo ${ }^{-0.5}$, and Albedo ${ }^{-1.5}$, respectively. Our method used here is similar to previous studies aiming to investigate the influences of sea ice on ocean heat uptake or the AMOC slow down in a warmer climate (e.g., Bitz et al. 2006; Liu et al. 2019). By examining the variability characteristics separately in each of the four simulations we identify the impact of the forcing on the characteristics of the variability.

\section{c. Subsurface warming drift run with the SPEAR_AM2 model}

These above sea ice albedo perturbations alter ocean stratification mainly from the surface ocean. We also use the SPEAR_AM2 model control run to test the influence of substantial ocean subsurface perturbations on the SO internal variability (see more details in section 4). The SPEAR_AM2 model provides us a good opportunity to investigate whether our conclusions are dependent on perturbation methods (surface vs subsurface perturbations) and dependent on models (SPEAR_ LO vs SPEAR_AM2).

\section{d. Low-frequency variability over Antarctica in paleoclimate reconstructions}

The simulated SO variability and its relationship to the ocean mean state can be evaluated using paleoclimate reconstructions. A few marine records cover the past millennia in the Southern Ocean, mainly located on the continental shelf and in particular close to the Antarctic Peninsula and in the Ross Sea. However, they have generally at best a multidecadal resolution, a majority having only centennial resolution. Furthermore, their dating uncertainties can typically reach several decades at least (e.g., McGregor et al. 2015; Thomas et al. 2019). They are thus not appropriate to study the multidecadal variations analyzed here. By contrast, ice core data covering the past millennia have a resolution from annual to a few years, with a low dating uncertainty. We have thus chosen to analyze a recent compilation performed in the framework of the PAGES Antarctica2k working group (Stenni et al. 2017). Based on 112 ice core water stable isotopic records, they provide temperature reconstructions for seven regions: the East Antarctic Plateau, Wilkes Land Coast, Weddell Sea Coast, Antarctic Peninsula, West Antarctic Ice Sheet, Victoria Land Coast/Ross Sea, and Dronning Maud Land Coast (see Fig. 1 in Stenni et al. 2017). The temperature retrievals from ice core isotopic records over these regions are based on the isotope-temperature relationship from a composite-plus-scaling approach (hereafter CPS), the ECHAM5-wiso model simulation nudged to ERA-Interim (hereafter ECHAM) and the Nicolas 

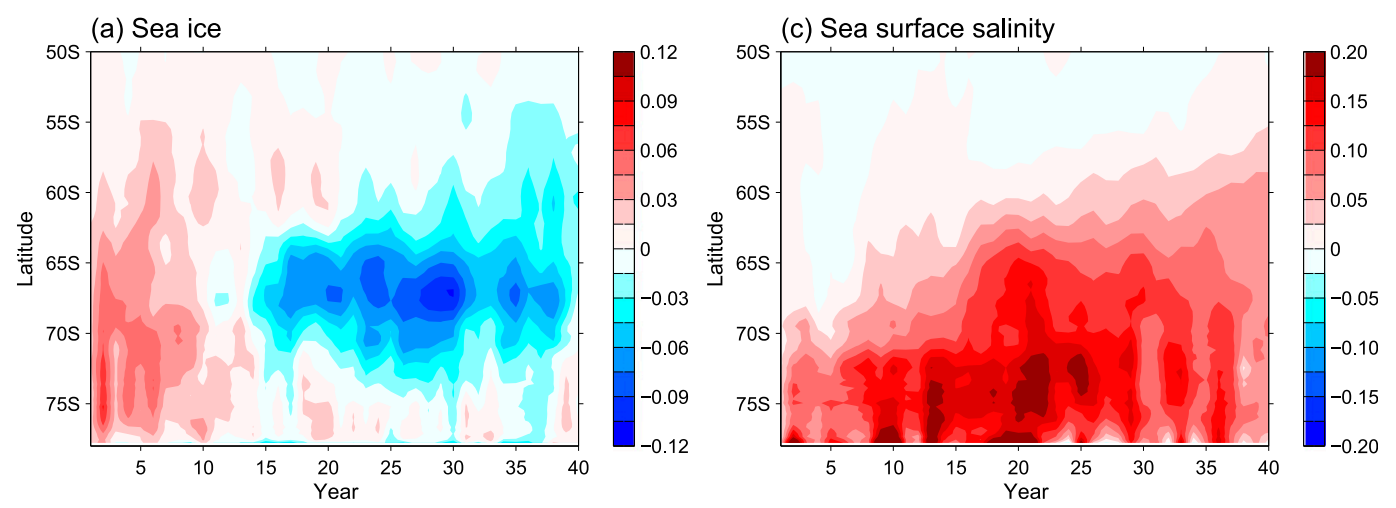

(b) SST
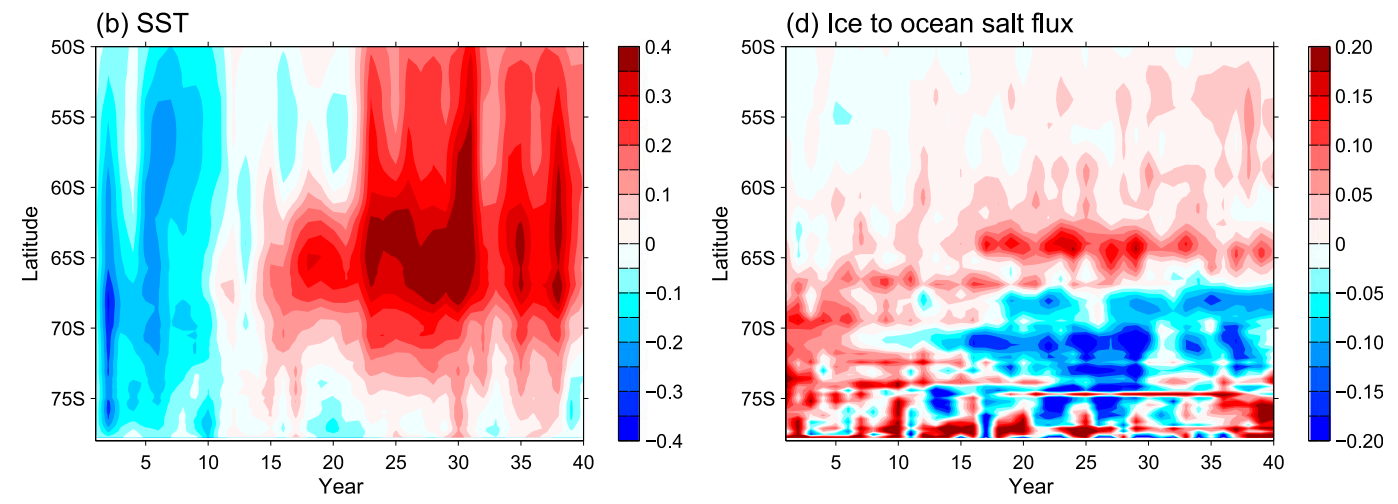

FIG. 2. Time evolutions of zonal mean (a) sea ice concentration (unit is $100 \%$ ), (b) SST $\left({ }^{\circ} \mathrm{C}\right.$ ), (c) sea surface salinity (psu), and (d) ice to ocean salt flux $\left(5 \times 10^{-6} \mathrm{~kg} \mathrm{~m}^{-2} \mathrm{~s}^{-1}\right)$ responses in the Albedo ${ }^{+1.5}$ EN run.

and Bromwich (2014) variance method (hereafter NB2014). Therefore, we have three temperature datasets in total based on different scaling methods (CPS, ECHAM, and NB2014) over the Antarctic continent, which is separated into seven different regions.

\section{SO responses to the sea ice albedo perturbation}

\section{a. Mean state responses}

We show in Fig. 2 the SO zonal mean sea ice concentration (SIC), SST, sea surface salinity (SSS), and ice to ocean salt flux evolutions in the Albedo ${ }^{+1.5}$ EN (difference between the ensemble mean of 10 perturbation experiments and the corresponding sections of control run). Perturbed by a positive sea ice albedo anomaly, the SIC and SST display two phases of their responses: a fast SIC increasing (negative SST) response south of $50^{\circ} \mathrm{S}$, followed by a slow SIC decreasing (positive SST) response. The transition between the two phases is seen after about 10 years. The initial SIC and SST anomalies are of significant magnitude, although they are slightly weaker than the subsequent slow responses. The fast response is a direct effect of sea ice albedo anomaly. As displayed in the heat budget (Fig. 3), the initial cooling is largely associated with the shortwave radiation forcing that shows a strong reduction (Fig. 3e). The positive sea ice albedo anomaly reflects more shortwave reflection to outer space, thereby causing lower SST and increased sea ice increase at the ocean surface.
Heat budget analysis (Fig. 3) also reveals that the slow warming response south of $65^{\circ} \mathrm{S}$ after 10 years is mainly due to the vertical mixing term (Fig. 3c), while the temperature advection (Figs. 3a,b) and surface heat flux (Figs. 3e,f) play roles in the warming response north of $65^{\circ} \mathrm{S}$. The contribution of the lateral neutral diffusion term is negligible compared to other terms (Fig. 3d). A close examination finds that the enhanced vertical mixing primarily results from the persistently positive salinity anomalies in the surface (Fig. 2c), corresponding to a weakening of ocean stratification (Fig. 4a). The sea ice increase in the initial years is accompanied by increased brine rejection, which results in increased equivalent salt fluxes from ice to ocean (Fig. 2d). The positive salinity anomaly accumulates at the surface, gradually reduces the ocean stratification (Fig. 4a), and eventually enhances the vertical mixing and spins up the AABW cell (Fig. 4b). The enhanced vertical mixing after $\sim 10$ years brings subsurface warm and salty waters to the surface, generating high SST (Fig. 2a) and positive salinity anomalies in the surface (Figs. 2b,c). Thus, the initially positive SSS anomalies are primarily due to brine rejection as a result of direct sea ice albedo perturbation, while the positive SSS anomalies after $\sim 10$ years mainly arise from the vertical mixing of subsurface salty water due to weakened ocean stratification. The ice to ocean salt flux contributes negatively to the SSS anomaly in the second stage ( $~ 10$ years later) (Fig. $2 \mathrm{~d}$ ) because the convective warming in the deep convection region (south of $65^{\circ} \mathrm{S}$ ) leads to a sea ice retreat at that time. 
(a) Horizontal advection

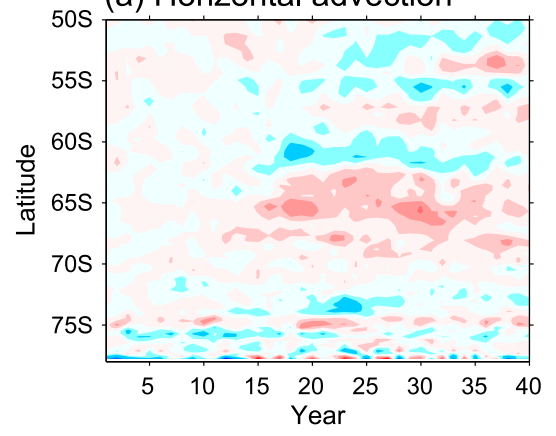

(d) Diffusion

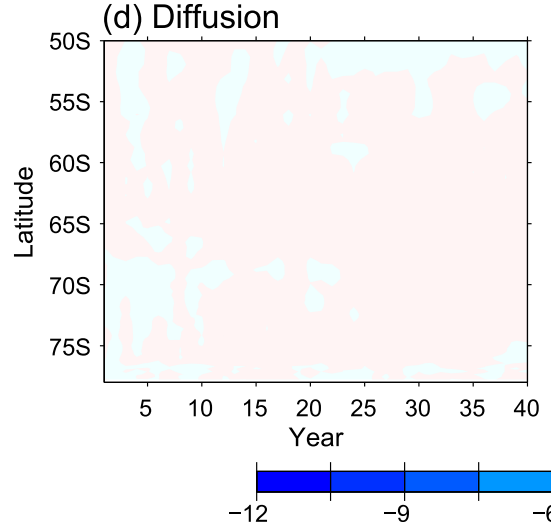

(b) Vertical advection

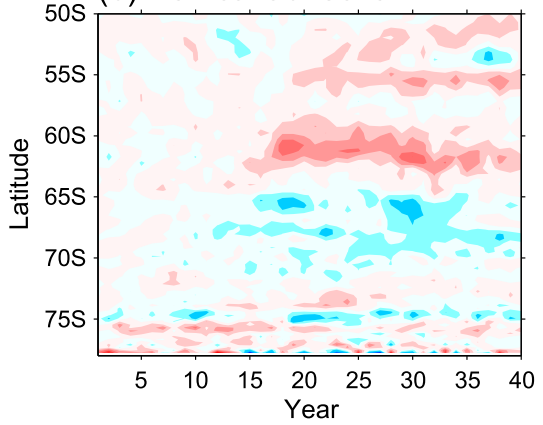

(e) Shortwave radiation

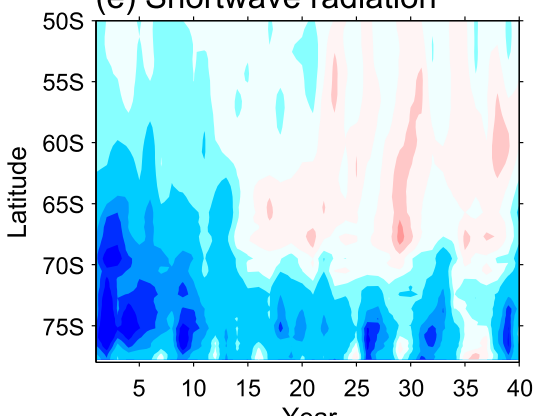

(c) Vertical mixing

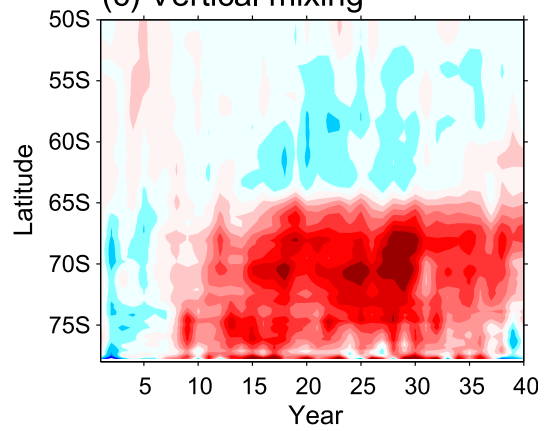

(f) Nonsolar heat flux

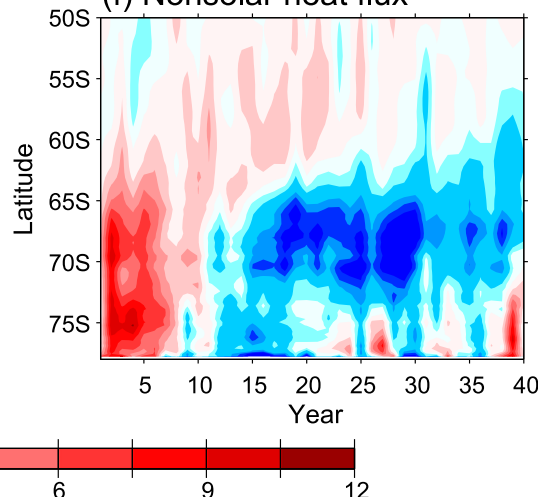

FIG. 3. Heat budget analysis for the zonal mean SST evolution in the Albedo ${ }^{+1.5}$ EN run. Shown are the contributions $\left(\mathrm{W} \mathrm{m}^{-2}\right)$ from (a) horizontal advection, (b) vertical advection, (c) vertical mixing, (d) lateral diffusion, (e) net shortwave radiation, and (f) nonsolar heat flux terms.

The positive contribution of advection terms to the second stage warming consists of two main components: the anomalous temperature gradient by the mean current and the mean temperature gradient by the anomalous current. Here we find that both components play positive roles. On one hand, the convective warming south of $65^{\circ} \mathrm{S}$ weakens the meridional temperature gradient, which increases the warm temperature advection by the mean northward Ekman current. On the other hand, the weakened meridional temperature gradient decreases the low atmosphere baroclinicity in the region of maximum eddy growth, which leads to an anomalous easterly over the SO (e.g., Zhang et al. 2019). The anomalous easterly induces the warm temperature advection by the anomalous southward Ekman flow (Figs. 5a,b). This also leads to an upwelling of subsurface warm water from below to the north due to mass conservation (Figs. 3a,b). Overall, the temperature advection spreads the warm temperature anomaly in the deep convection regions (south of $65^{\circ} \mathrm{S}$ ) to the north and almost covers the entire SO. The anomalous easterly also reduces the surface heat flux and favors the development of surface warming (Fig. 3f) through the positive wind-evaporation-SST (WES) feedback (e.g., Xie and Saito 2001).

\section{b. Internal low-frequency variability responses}

We show in Fig. 6 the SO long-term mean (time-averaged over the full 600 years) stratification versus SSS relationship in the Control, Albedo ${ }^{+1.5}$, Albedo $^{+0.5}$, Albedo $^{-1.5}$, and Albedo $^{-0.5}$ experiments. Consistent with the responses in the Albedo ${ }^{+1.5}$ EN experiment, the sea surface water in the Albedo ${ }^{+1.5}$ and Albedo $^{+0.5}$ is saltier and the ocean stratification is weaker compared to the Control run. On the contrary, the SSS becomes smaller and the ocean stratification becomes stronger in the Albedo $^{-1.5}$ and Albedo ${ }^{-0.5}$ runs. Figure 7 displays the AABW cell time series in different simulations, with the amplitude of variability listed in the bottom right corners. In the control simulation, the amplitude of AABW cell variability is about $4.5 \mathrm{~Sv}$. In the Albedo $^{+1.5}$ and Albedo ${ }^{+0.5}$ runs, the convection amplitude becomes smaller, changing from 4.5 to 3.5 and $4.1 \mathrm{~Sv}$, respectively (Fig. 7c vs Figs. 7a,b). In the Albedo ${ }^{-1.5}$ and Albedo ${ }^{-0.5}$ runs, the convection amplitude increases to 7.3 and $6.1 \mathrm{~Sv}$, respectively (Fig. 7c vs Figs. 7d,e). The low-frequency convection period also exhibits some changes. The convection period shifts from the original 80 years in the control run to 58 years in the Albedo ${ }^{+1.5}$ run and 73 years in the Albedo ${ }^{+0.5}$ run (Fig. 8). In the Albedo ${ }^{-0.5}$ and Albedo ${ }^{-1.5}$ runs, the convection period increases to 90 and 115 years, respectively (Fig. 8). In brief, the model under a weak ocean stratification background (e.g., Albedo ${ }^{+1.5}$ ) tends to have convection variability of smaller amplitude and shorter period and vice versa.

We then examine why the SO convection variability has such amplitude changes. Figure 9 shows Hovmöller diagrams of annual mean temperature and salinity profiles averaged over 
(a) Density difference response $(1000 \mathrm{~m}-0 \mathrm{~m})$

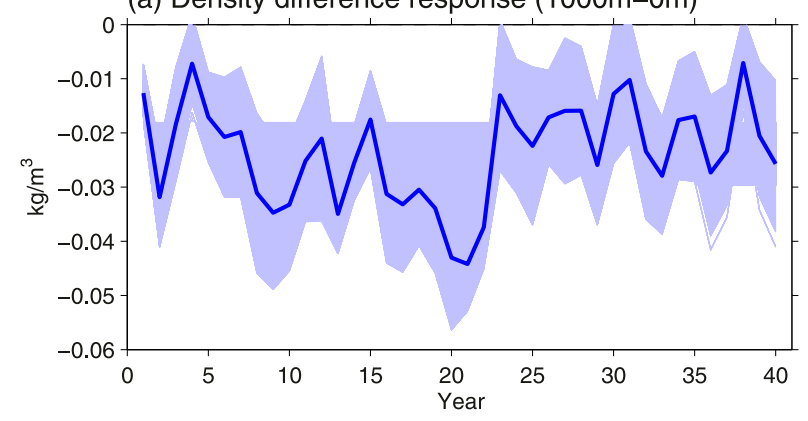

(b) AABW cell response

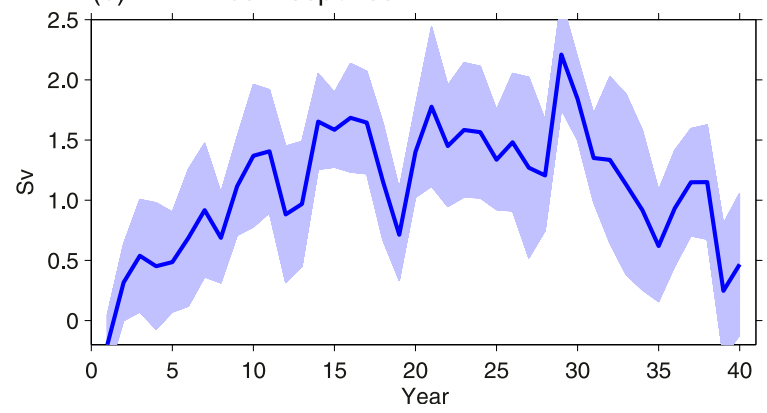

FIG. 4. (a) Southern Ocean area averaged (south of $50^{\circ} \mathrm{S}$ ) response of potential density difference $\left(\mathrm{kg} \mathrm{m}^{-3}\right)$ between the subsurface $1000 \mathrm{~m}$ and surface in the Albedo ${ }^{+1.5}$ EN run. The blue solid line denotes the ensemble mean, while the light blue shading denotes the ensemble spread (one standard deviation of 10 ensembles). (b) As in (a), but for the AABW cell responses (Sv). The $40-\mathrm{yr}$ averaged density and $\mathrm{AABW}$ responses are significant at $90 \%$ confidence level using the Student's $t$ test.

the SO. The first impression from Fig. 9 is that the SO is dominated by periodic recharge and discharge of subsurface heat and salt reservoirs. When the convection is strong, the temperature anomaly distribution is relatively homogeneous in the subsurface layer, which corresponds to anomalous positive SST and sea ice retreat in the surface because of convective warming. The weak convection phase, however, is characterized by a strong heat buildup in the subsurface layer. By comparison with these five simulations, we can see the subsurface heat reservoir in the Albedo ${ }^{-1.5}$ run is the largest (Fig. 9e), followed by the Albedo ${ }^{-0.5}$ run with the second largest heat reservoir (Fig. 9d). The heat reservoirs in these two runs are larger than that in the Control simulation (Figs. 9d,e vs Fig. 9c). On the contrary, the heat reservoir in the Albedo ${ }^{+0.5}$ run is smaller than that in the Control simulation (Fig. 9b vs Fig. 9c). The subsurface heat buildup in the Albedo ${ }^{+1.5}$ run is weak as well and has the smallest heat reservoir (Fig. 9a). As mentioned by previous studies (e.g., Martin et al. 2013; Dufour et al. 2017), the subsurface heat reservoir buildup is a preconditioning of the SO deep convection. The accumulated heat in the subsurface spreads over time, gradually destabilizes the ocean stratification from below, and eventually drives the convection. During the strong convection regime, the subsurface heat depletes and releases a large amount of heat to the atmosphere and space. The larger-thannormal heat reservoir has more energy saved in the subsurface ocean, which has potential to drive a stronger-than-normal deep convection and therefore corresponds to a larger amplitude of deep convection oscillation and vice versa.

To investigate what processes cause the magnitude differences of the subsurface heat reservoir, we show in Fig. 10 the SO heat budget at $1550 \mathrm{~m}$ for the Albedo ${ }^{+1.5}$ and Albedo ${ }^{-1.5}$ runs. The subsurface heat in both runs is primarily balanced by the advection and vertical mixing terms, while the diffusion term plays a much smaller role. The heat reservoir is mainly replenished through the advection term, particularly the horizontal component (not shown). The Weddell Gyre meridionally advects the warm lower circumpolar deep water to the south (e.g., Dufour et al. 2017), leading to heat convergence and a buildup of the subsurface heat reservoir. The depletion of subsurface heat is mainly through vertical mixing, which brings heat upward and eventually releases to the atmosphere. During the weak convection regime (white area in Fig. 10), it is clearly seen that the heat tendency term in the Albedo ${ }^{-1.5}$ run is larger than that in the Albedo ${ }^{+1.5}$ run (black lines in Figs. 10a and 10b), consistent with the larger heat reservoir shown in Figs. 9e and 9a. This difference mainly arises from the smaller vertical mixing term, whereas the warming effects of advection term are comparable (see numbers in Fig. 10). The cooling effect from vertical mixing in the Albedo ${ }^{+1.5}$ run is larger than that in the Albedo $^{-1.5}$ run, resulting in a strong and frequent depletion of the subsurface heat reservoir. The differences in vertical mixing shown here that account for $33 \%-50 \%$ of the mean response in Albedo ${ }^{-0.5}$ run are strongly associated with the background ocean stratification mean state. The weak ocean stratification in the Albedo ${ }^{+1.5}$ run is in favor of generating the gravitational instability (Dufour et al. 2017), which tends to enhance the vertical mixing of unstable water columns and thus results in an erosion of the subsurface heat reservoir. The opposite is also established for the Albedo ${ }^{-1.5}$ run.

In contrast to the temperature evolution, the large salinity anomalies associated with the deep convection variability are mainly concentrated over the surface (Figs. 9f-j). The positive salinity anomalies at the surface favors the occurrence of deep convection (e.g., Kjellsson et al. 2015) and the surface freshwater cap is also a precursor for the weakening of deep convection (e.g., Pierce et al. 1995; Martin et al. 2013). The surface sea ice albedo perturbations and the associated ocean stratification changes determine the SSS responses. In the Albedo ${ }^{+1.5}$ and Albedo ${ }^{+0.5}$ runs, both of the fast and slow responses favor positive SSS anomalies in the surface (e.g., Fig. 2c). The sea surface water overall is saltier in the Albedo ${ }^{+1.5}$ and Albedo ${ }^{+0.5}$ runs than that in the Albedo $^{-1.5}$ and Albedo ${ }^{-0.5}$ runs.

The ocean stratification contributed primarily from salinity in the SO eventually determines the period of internal deep convection variability. The Albedo ${ }^{+1.5}$ and Albedo ${ }^{+0.5}$ (Albedo $^{-1.5}$, Albedo $^{-0.5}$ ) runs with a weak (strong) ocean stratification tend to have a shorter (longer) convection period. The weak stratification is more vulnerable to surface or subsurface disturbances. The anomalous dry atmospheric conditions, brine rejection from sea ice, or subsurface heat buildup are more prone to induce deep convection under a weak stratification mean state. On the other hand, the frequent deep convection can continuously erode the stratification, thus generating a positive feedback. Similarly, changes in surface freshwater, whether from advection, ice melt, or precipitation, are easier to alter the vertical 
(a) Zonal mean zonal wind stress response

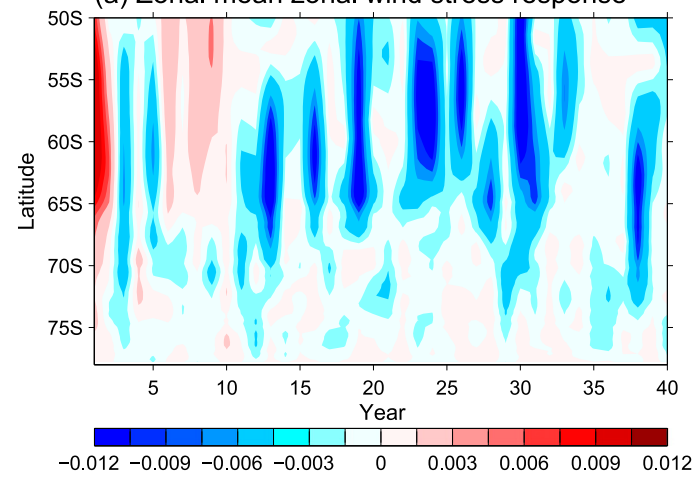

(b) Zonal mean merional current response

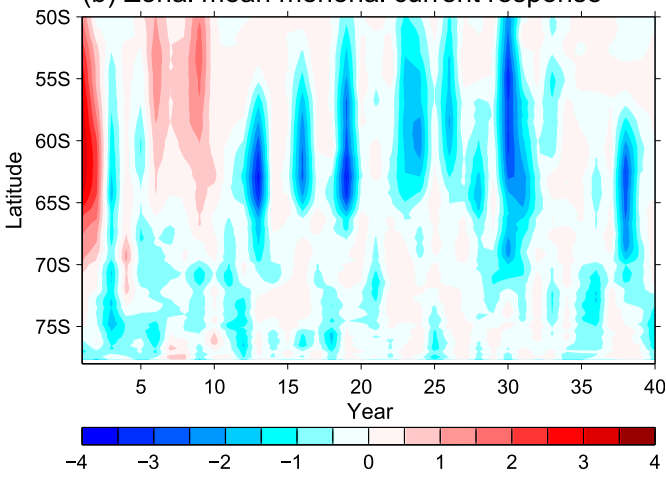

FIG. 5. Time evolutions of zonal mean (a) zonal wind stress $\left(\mathrm{N} \mathrm{m}^{-2}\right)$ and (b) surface meridional current $\left(0.001 \mathrm{~m} \mathrm{~s}^{-1}\right)$ responses in the Albedo ${ }^{+1.5}$ EN run.

stratification and convection, thereby creating conditions conducive to flipping from a strong to a weak convective phase, or vice versa (e.g., Lique and Thomas 2018). The sea ice state may also contribute positively to the convection period (not shown). The sea ice extent is relatively small and of shorter duration during the weak convection regime in the Albedo ${ }^{+1.5}$ run; accordingly, the destabilization factors such as the subsurface heat take a shorter time to break through the sea ice cap and subsequently initiate deep convection there and vice versa.

\section{SO responses to the subsurface warming drift perturbation}

These above sea ice albedo perturbations alter ocean stratification mainly from the surface. We also use the SPEAR_ AM2 control run to test the influence of substantial ocean subsurface perturbations on the SO internal variability. Similar to other GFDL fully coupled models (e.g., Delworth et al. 2012, 2020), the SPEAR_AM2 model has temporal drifts that vary with depth. The global mean net radiation at the top of atmosphere shows positive values in the initial years that slowly decline over time (Fig. 11a). The long-term average is above zero (Fig. 11a), indicating the climate system is gaining energy. This net energy gain is then reflected in the surface air temperature as a warming trend (Fig. 11b) and is eventually stored in the subsurface ocean by the wind-driven subduction and thermohaline ventilation processes (Fig. 11c). The magnitude of subsurface warming drift varies model by model, in which the resolved or parameterized restratifying effects of ocean mesoscale eddies are proposed to play important roles (e.g., Delworth et al. 2012). The SPEAR_AM2 model has a strong subsurface warming drift. Although investigating what processes cause this drift is beyond our focus, this strong subsurface warming drift indeed provides us a good opportunity to examine how the SO responds to a subsurface warming perturbation. The SPEAR_AM2 model also allows us to investigate whether our conclusions are dependent on model formulation by comparing with the SPEAR_LO responses.

Due to the subsurface warming drift, the SO area averaged density decreases in the subsurface ocean and therefore the ocean stratification becomes weaker during the whole 3000 years (Fig. 12a). Associated with this change, the SO deep convection experiences three different regimes revealed by the wavelet analysis (Fig. 12b). In the initial 500 years, the ocean stratification is relatively strong and there are no obvious oscillations for the convection (Fig. 12b). Thereafter, the ocean stratification further weakens, and the deep convection starts to oscillate. The oscillation has a pronounced period of around 140 years during years 1001-2000, with the strongest amplitude throughout the entire integration (Fig. 12b). After about 2000 years, the ocean stratification becomes even weaker. Note that the ocean warming drift below $2000 \mathrm{~m}$ becomes significant and is comparable to the warming in the upper $200-1000 \mathrm{~m}$ at this time (Fig. 11c). The SO convection still oscillates but with a much shorter period (around $40 \mathrm{yr}$ ) and with a smaller amplitude (Fig. 12b). These results seem to be consistent with the conclusion we obtained in the ice albedo perturbation experiments in section 3. That is, the stronger (weaker) stratification

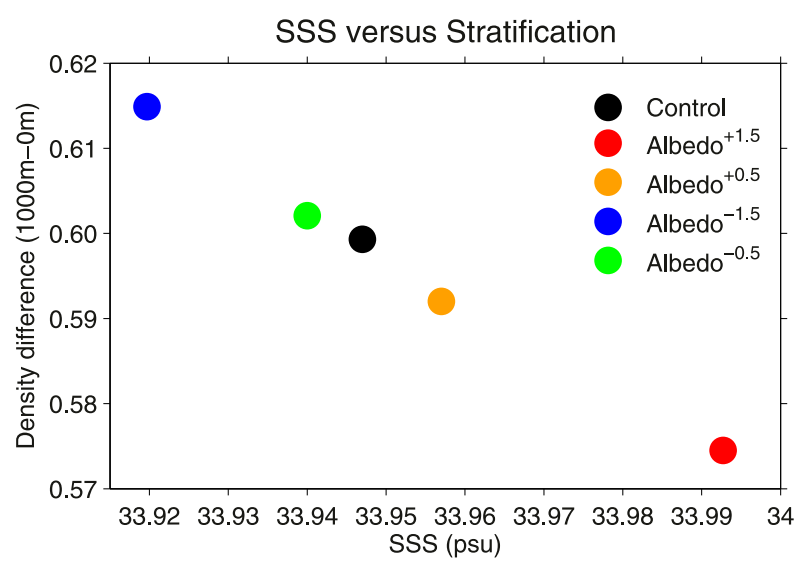

FIG. 6. Scatterplot of the time mean sea surface salinity (SSS, PSU) vs time mean ocean stratification $\left(\mathrm{kg} \mathrm{m}^{-3}\right)$ measured by the potential density difference between 1000 and $0 \mathrm{~m}$. The SSS and stratification changes in perturbation experiments compared to the Control simulation (albedo runs minus control run for both variables) are significant at $90 \%$ confidence level based on a two-tailed Student's $t$ test. 
(a) Albedo ${ }^{+1.5}$

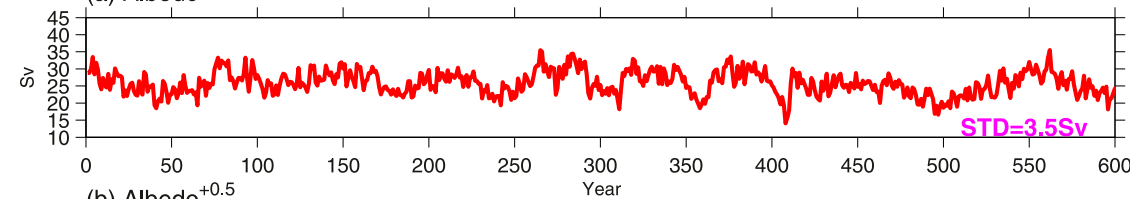

(b) Albedo +0.5

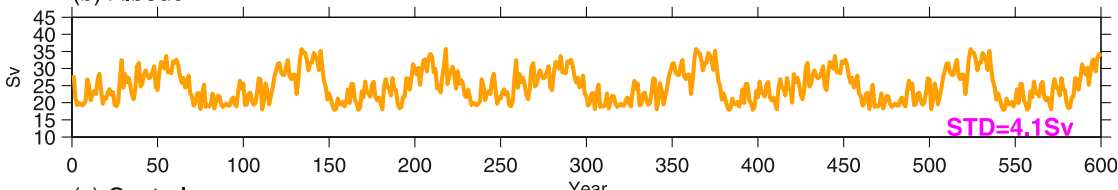

(c) Control

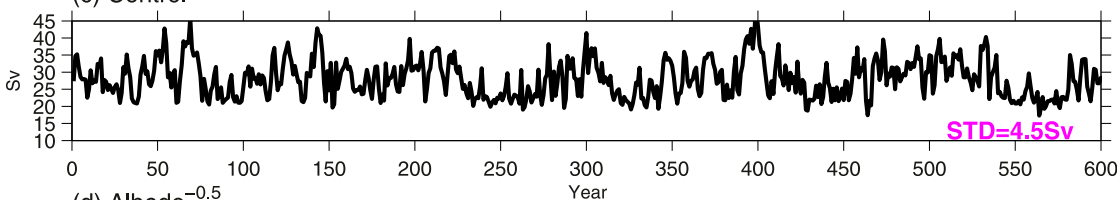

(d) Albedo -0.5

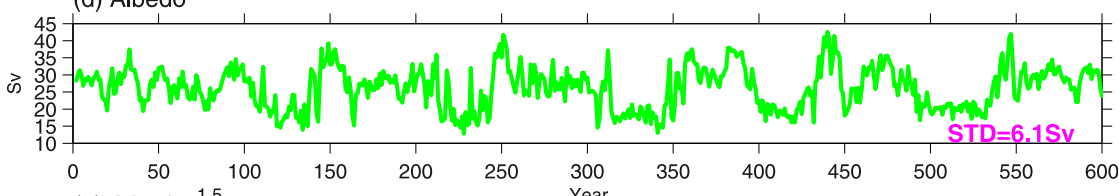

(e) Albedo $^{-1.5}$

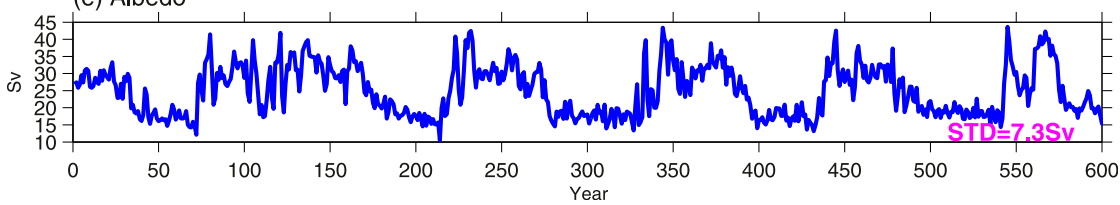

FIG. 7. Time series of the AABW cell index (Sv) in the SPEAR_LO (a) Albedo ${ }^{+1.5}$, (b) Albedo ${ }^{+0.5}$, (c) Control, (d) Albedo ${ }^{-0.5}$, and (e) Albedo ${ }^{-1.5}$ runs. The standard deviation

(STD) of time series is given in the lower right corner of each panel.

is in favor of generating convection with larger (smaller) amplitude and longer (shorter) period if the oscillation occurs.

Note that the strength of the AABW cell represents the convection accumulated in the entire SO. Although the convection variability during years 1001-2000 looks much stronger than that during years 2001-3000 (Fig. 12b), this is not true for every basin. We show in Fig. 13a the MLD variability during years 1001-2000 and 2001-3000, respectively. The open ocean deep convection variability in the Weddell Sea is much stronger in years 2001-3000 than that in years 1001-2000, while the opposite is true in most of other basins such as the Ross Sea (Figs. 13a,b). The sharp contrast of convection variability between the Weddell Sea and the Ross Sea is also seen from the MLD time series (Fig. 13c). During years 1001-2000, both the Weddell and Ross Seas have strong convection events, although the convection in the Ross Sea is weaker than that in the Weddell Sea. Because of the resonance between the two basins, the AABW cell shows the strongest strength during this period (Fig. 12b). During years 2001-3000, the Ross Sea convection events, however, become much weaker and almost disappear. During this period, the Weddell Sea convection becomes dominant. The Weddell Sea convection during this time is even stronger than that during years 1001-2000. Due to the absence of Ross Sea contribution, the AABW cell strength shows a weaker magnitude during years 2001-3000 compared to years 1001-2000 (Fig. 12b). It is worth noting that this basin dependence of convection variability does not exist in the sea ice perturbation experiments, probably due to the fact that the surface perturbation is quite uniform.

What physical processes cause these convection differences in these two basins in the SPEAR_AM2 model? We show in Fig. 13d the ocean stratification evolutions in both the Ross and

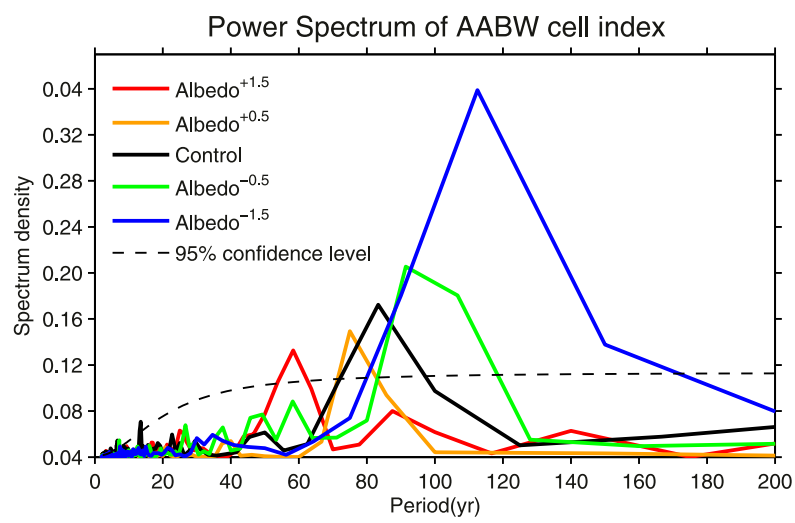

FIG. 8. Power spectrum of the normalized AABW cell index in the SPEAR_LO Albedo ${ }^{+1.5}$, Albedo ${ }^{+0.5}$,Control, Albedo ${ }^{-0.5}$, and Albedo $^{-1.5}$ experiments. 


\section{Temperature}

(a) Albedo ${ }^{+1.5}$

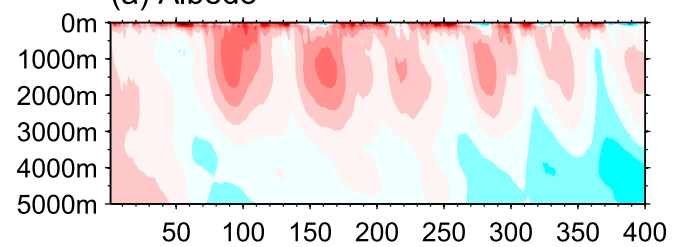

(b) Albedo ${ }^{+0.5}$

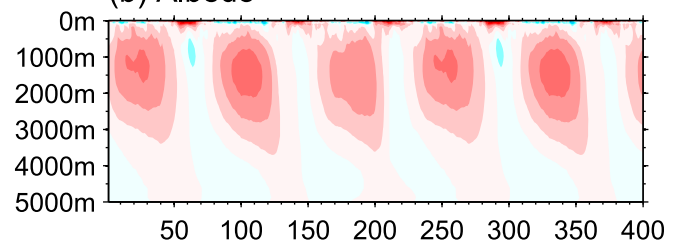

(c) Control

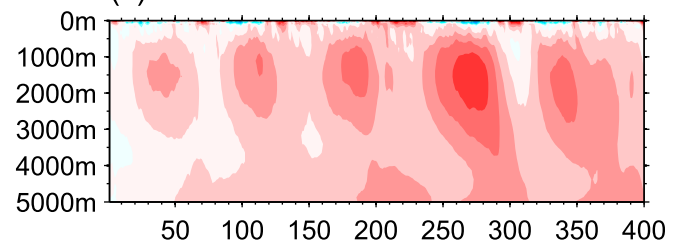

(d) Albedo ${ }^{-0.5}$

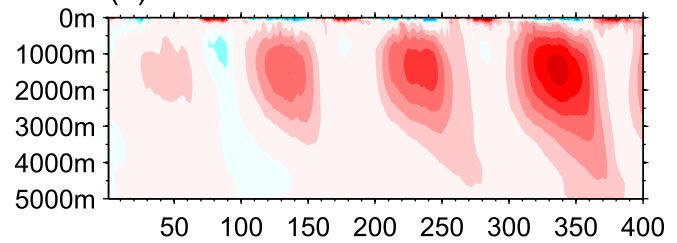

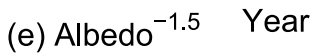

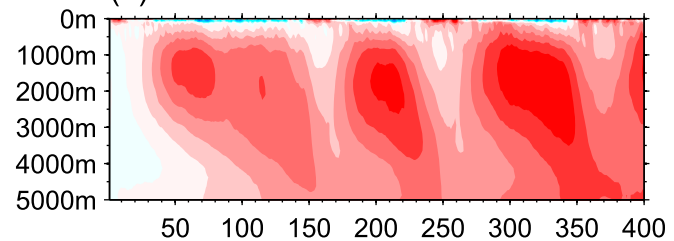

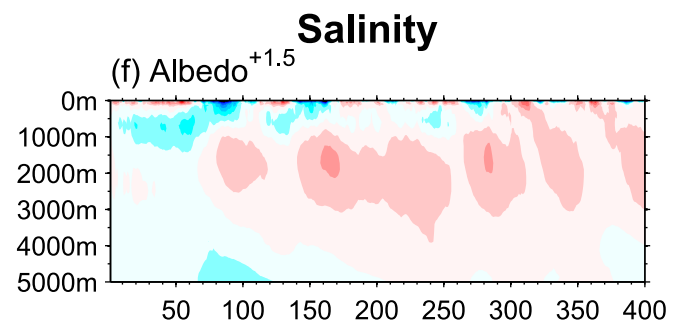

(g) Albedo +0.5

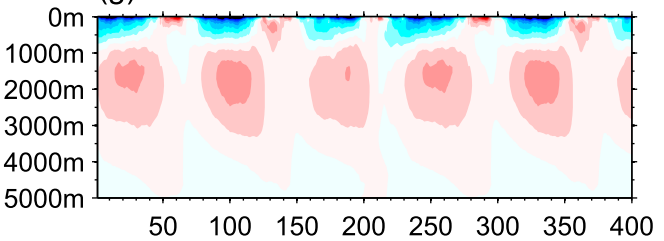

(h) Control

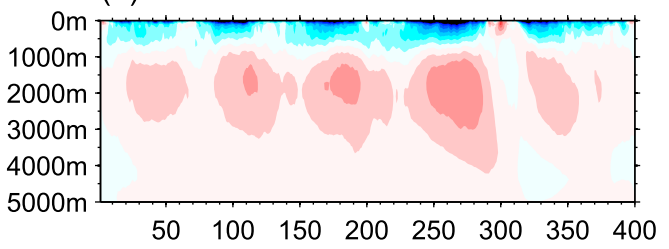

(i) Albedo ${ }^{-0.5}$
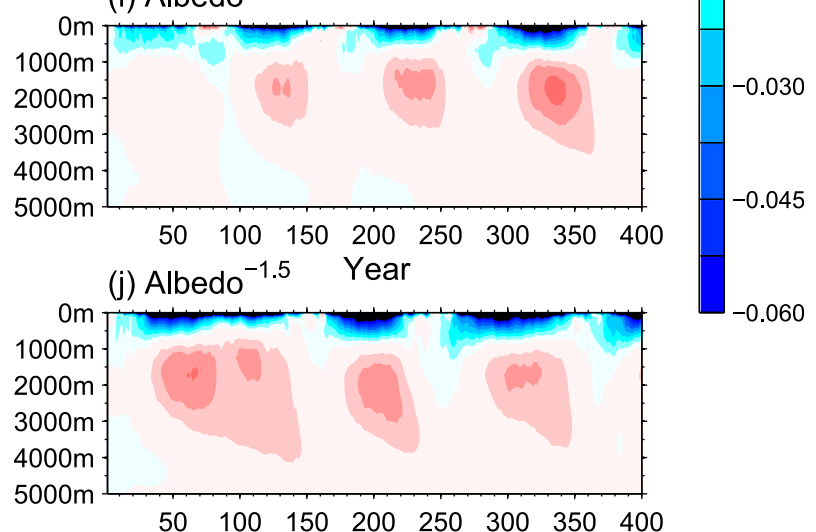

FIG. 9. Time series of annual mean subsurface (left) temperature $\left({ }^{\circ} \mathrm{C}\right.$ ) and (right) salinity (psu) profiles averaged over the Southern Ocean (south of $50^{\circ} \mathrm{S}$ ) in the SPEAR_LO (a),(f) Albedo ${ }^{+1.5}$, (b), (g) Albedo ${ }^{+0.5}$, (c),(h) Control, (d),(i) Albedo ${ }^{-0.5}$, and (e),(j) Albedo ${ }^{-1.5}$ runs. To highlight the subsurface heat and salt reservoirs, the initial state (first year) is removed from the temperature and salinity evolutions.

Weddell Seas. The ocean stratification becomes weaker in both seas in the initial several hundreds of years due to the subsurface warming drift (Fig. 11c). The ocean stratification change is largely related to the subsurface density decrease rather than the surface density changes during this time (not shown). After about 300 years, the ocean stratification evolution starts to bifurcate in these two basins, with a continuous weakening in the Weddell Sea and a gradual strengthening in the Ross Sea. Note that the Ross Sea stratification is quite strong in years 2001-3000, which is even stronger than the initial 100 years. Therefore, the Ross Sea strong convection events nearly disappear during this period. This is in agreement with previous studies in which the increased stratification was found to hamper the formation of SO convection (de Lavergne et al. 2014; Kjellsson et al. 2015). Further examination reveals that the Ross Sea density decreases in both the surface and subsurface oceans. However, the surface density decreases much faster than that in the subsurface ocean (not shown), resulting in an enhanced ocean stratification trend over the Ross Sea. The surface density change here is largely associated with the surface freshwater flux input (Fig. 13e). The warming SST drift due to net radiation gain and convective warming in the Ross Sea (not shown) gradually enhances the precipitation and sea ice melt in the local region. These freshwater-induced density changes eventually overwhelm the subsurface density decrease due to warming drift during years 2001-3000.

The processes causing convection over the Weddell Sea are completely different from those in the Ross Sea. As shown in 
(a) Albedo ${ }^{+1.5}$

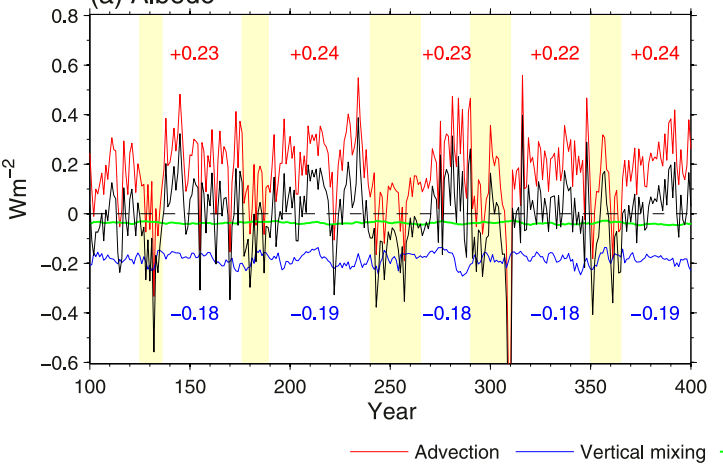

(b) Albedo ${ }^{-1.5}$

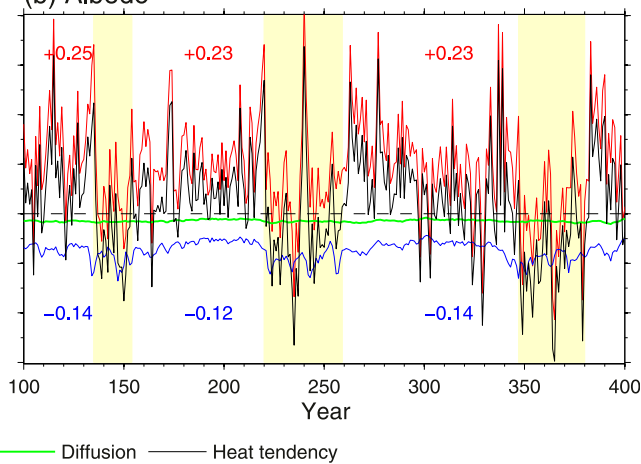

FIG. 10. Time series of heat budget terms $\left(\mathrm{W} \mathrm{m}^{-2}\right)$ averaged in the Southern Ocean (south of $\left.50^{\circ} \mathrm{S}\right)$ interior ocean (at $1550 \mathrm{~m}$ ) in the (a) Albedo ${ }^{+1.5}$ and (b) Albedo ${ }^{-1.5}$ runs. The red, blue, green, and black lines denote the advection, vertical mixing, lateral diffusion, and heat tendency terms, respectively. The yellow shadings denote the relatively strong convection regimes, while the white areas represent the weak convection regimes. The red (blue) numbers in this figure represent the heat gain (loss) averaged in the weak convection regimes by advection (vertical mixing).

Fig. 11c, the subsurface warming drift gradually penetrates to the deep ocean. The entire North Atlantic Deep Water (NADW) and Lower Circumpolar Deep Water (LCDW) become much warmer during years 2001-3000 compared to before (Fig. 14a). These warm waters can be continuously advected to the Weddell Sea subsurface ocean by the Weddell Gyre. It is worth noting that the AMOC continues to strengthen in the SPEAR_AM2 control run due to the weakened stratification

(a) Global mean radiative balance at top of atmosphere

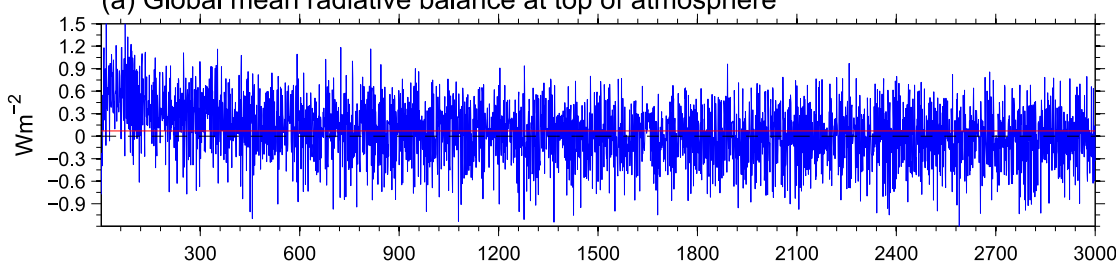

(b) Global mean surface air temperature

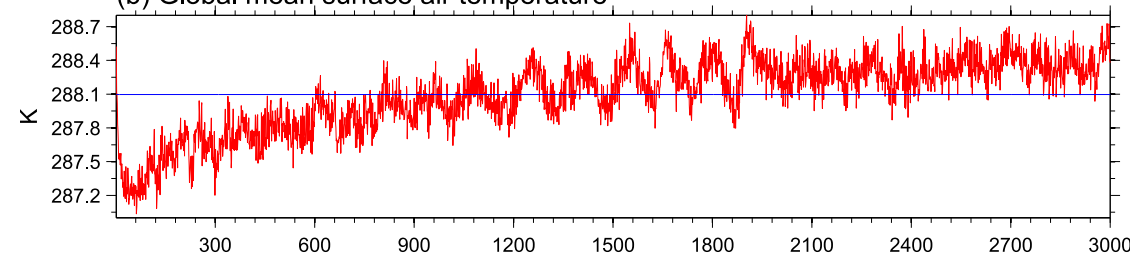

(c) Global mean subsurface ocean temperature drift from initial condition

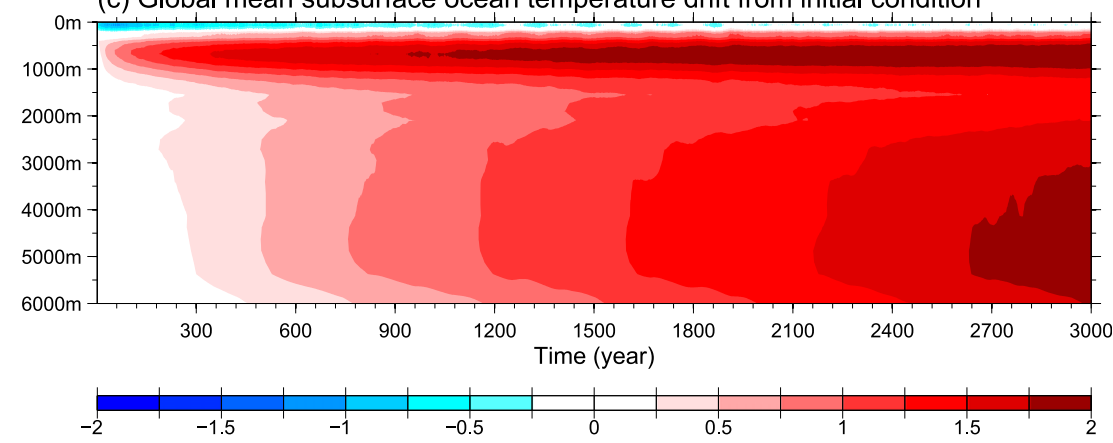

FIG. 11. Time evolutions of global mean (a) net radiative balance at the top of atmosphere $\left(\mathrm{W} \mathrm{m}^{-2}\right)$, (b) surface air temperature $(\mathrm{K})$, and (c) ocean temperature drift $\left({ }^{\circ} \mathrm{C}\right)$ from initial condition in the SPEAR_AM2 control simulation. The red and blue lines in (a) and (b) denote the time averaged values. 
(a) Density difference $(1000 \mathrm{~m}-0 \mathrm{~m})$ evolution averaged over the SO

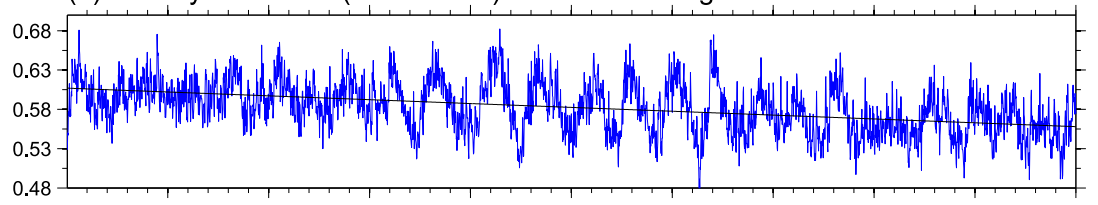

(b) Wavelet of the AABW cell index

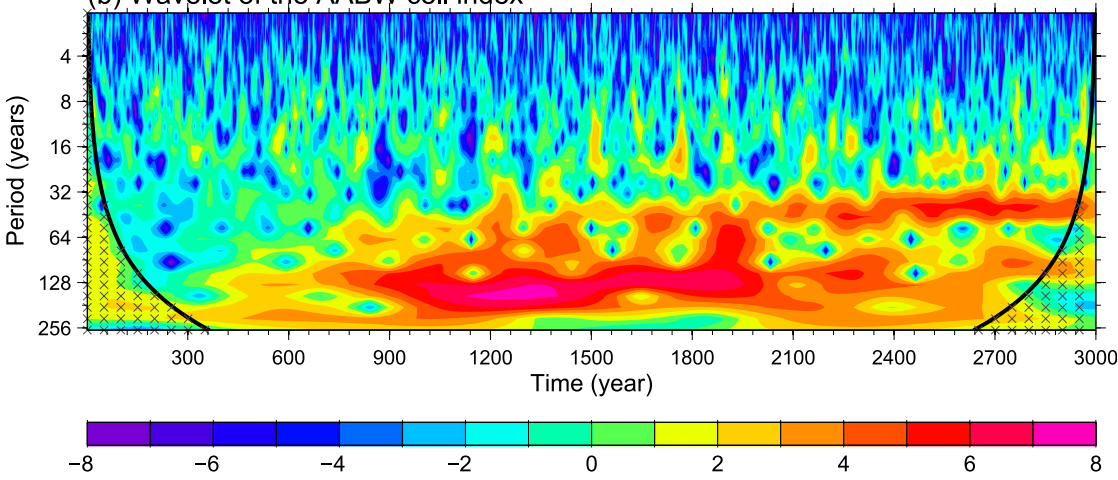

FIG. 12. Ocean stratification and the deep convection index in the SPEAR_AM2 model control simulation. (a) Time evolution of the Southern Ocean area mean potential density

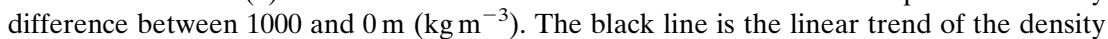
difference. (b) Wavelet analysis of the normalized AABW cell index. The crossing areas under the bold black curve indicate these values are not significant at $95 \%$ confidence level.

(not shown), which efficiently moves the net radiation gain to the deep ocean, providing a heat source for the Weddell Sea. Thus, the subsurface density decrease is always larger than that in the surface in the Weddell Sea, which induces a persistent ocean stratification weakening (Fig. 13d). This additional heat source also favors the buildup of a subsurface heat reservoir (Fig. 14b). By comparing years 1001-2000 with years 2001-3000, it is clearly seen that the strong subsurface heat buildup in the latter years is primarily associated with the temperature advection term, while the vertical mixing plays a negative role (Fig. 14c). The vertical mixing evolution is consistent with the ocean stratification changes. The weaker ocean stratification during years 2001-3000 corresponds to episodes of gravitational instability and enhanced vertical mixing cooling (Fig. 14c), which is consistent with the sea ice albedo experiments (Fig. 10) and the previous study by Dufour et al. (2017). The positive contribution of advection term here is dominated by the horizontal component (not shown). The Weddell Gyre brings the warmer-thanaverage NADW and LCDW to the Weddell Sea, leading to a heat convergence that builds up the subsurface heat reservoir. The strong heat buildup in the subsurface ocean eventually leads to a strong amplitude of convection variability. This is why the amplitude of MLD variability over the Weddell Sea is stronger during years 2001-3000 than that in years 1001-2000, although the ocean stratification is weaker in the latter. This is in stark contrast with the sea ice albedo experiments, which show that the weaker stratification background corresponds to a weaker amplitude of convection variability (Figs. 8-10). Since the sea ice albedo perturbation does not affect the NADW and LCDW properties in these experiments or there is no additional heat source from north, the vertical mixing term induced by the stratification change becomes a dominant factor to explain the subsurface heat reservoir differences (Fig. 10).

\section{SO centennial variability in paleoclimate records}

A question naturally arises: is there evidence in nature for the existence of this internal multidecadal to centennial variability seen in models? Given that the in situ observations over the SO are very sparse in both space and time, we turn our attention to the ice core isotopic records over the Antarctic continent. We analyzed the CPS, ECHAM, and NB2014 datasets and found that their temperature variations are almost in phase, although there are some magnitude differences (not shown). Given the similarity in the records, we only show results from the CPS dataset as an example. Figure 15 shows the surface temperature reconstructions from the CPS dataset in seven Antarctic regions. The temperature averaged over the whole Antarctic continent shows a long-term cooling trend, with the warmest period during 300-1000 CE and the coldest period in 1200-1900 CE (Fig. 15a). This cooling trend is hypothesized to be related to either solar insolation changes due to precession of the equinoxes or volcanic aerosols forcing (e.g., Stenni et al. 2017; McGregor et al. 2015). In addition to the trend, low-frequency variability is also clearly seen from these time series. As displayed in Fig. 16, the power spectra of these temperature time series show pronounced centennial variability in most regions, including the Wilkes Land Coast, the West Antarctic region, the Weddell Sea coast, the Victoria Land/Ross Sea region, and all of Antarctica as well. We can see a $\sim 130-180$-yr peak in the Weddell Sea and Antarctic Peninsula, although it is not significant at the $95 \%$ confidence 

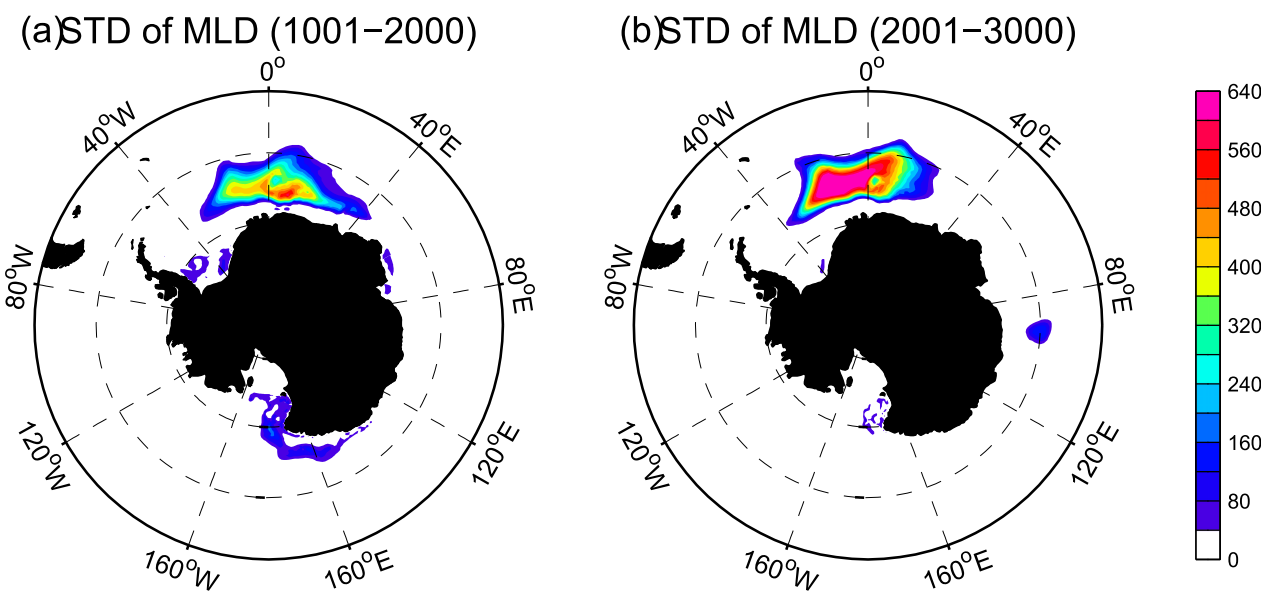

(c) MLD time series

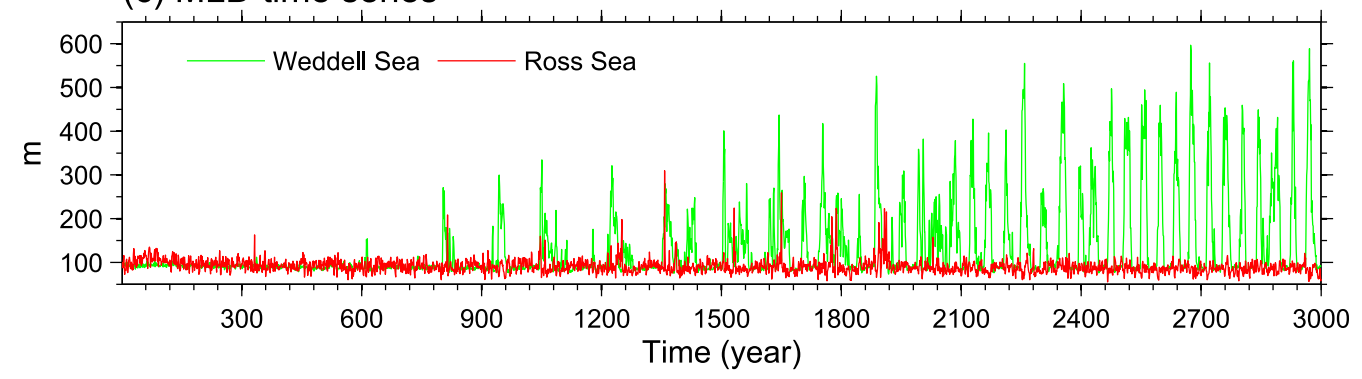

(d) Density difference $(1000 \mathrm{~m}-0 \mathrm{~m})$ time series

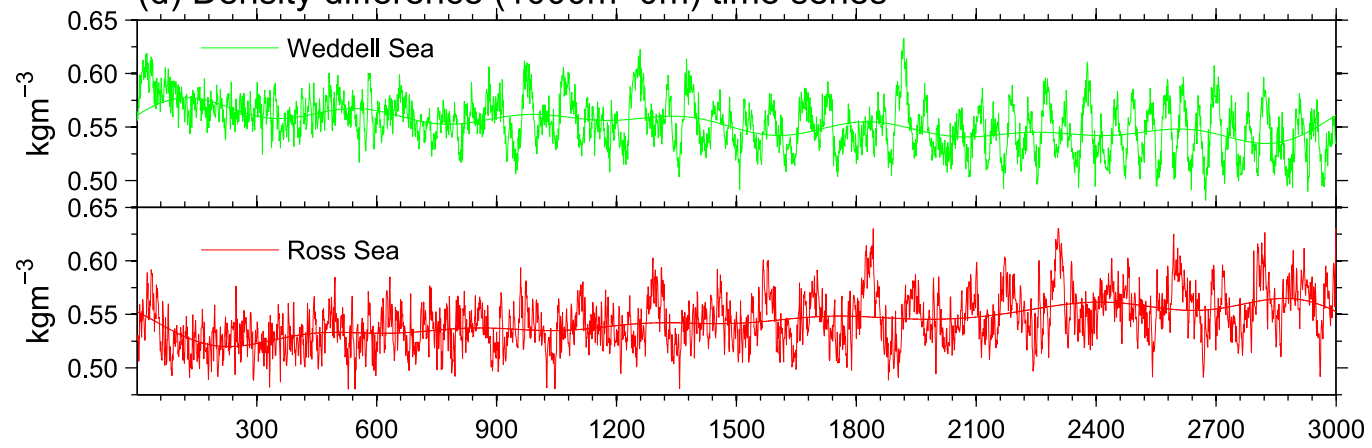

(e) Surface freshwater flux into the Ross Sea

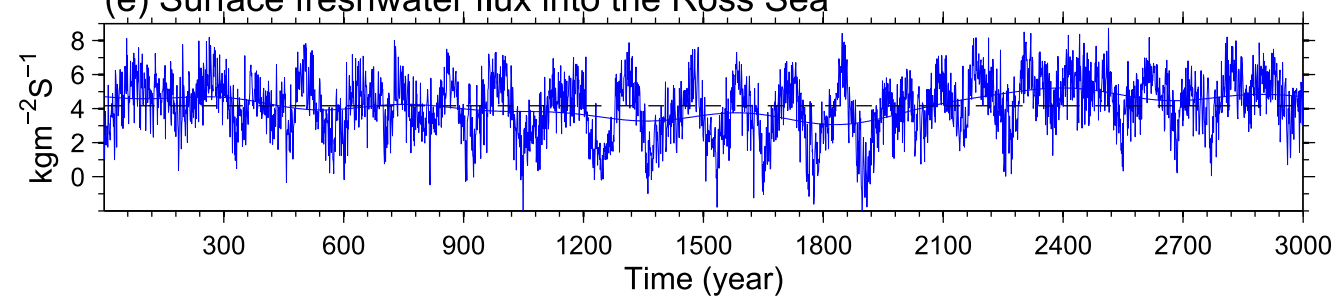

FIG. 13. Standard deviation of annual mean mixed layer depth (MLD; m) averaged over the years (a) 1001-2000 and (b) 2001-3000 in the SPEAR_AM2 control run. (c) Time evolutions of annual mean MLD (m) averaged over the Weddell Sea $\left(77^{\circ}-57^{\circ} \mathrm{S}, 60^{\circ} \mathrm{W}-20^{\circ} \mathrm{E}\right)$ and Ross Sea $\left(77^{\circ}-62^{\circ} \mathrm{S}, 150^{\circ}-185^{\circ} \mathrm{E}\right)$ regions. The MLD is calculated as the depth where the density difference between the surface is $0.03 \mathrm{~kg} \mathrm{~m}^{-3}$. (d) As in (c), but for the density difference $\left(\mathrm{kg} \mathrm{m}^{-3}\right)$ between 1000 and $0 \mathrm{~m}$. (e) Time evolutions of annual mean surface freshwater flux $\left(\mathrm{kg} \mathrm{m}^{-2} \mathrm{~s}^{-1}\right)$ into the Ross Sea. The overlaid smoothed lines in (d) and (e) are the 150-yr low-pass filtered time series. 
(a) Atlantic temperature (yr2001-3000)-(yr1001-2000)

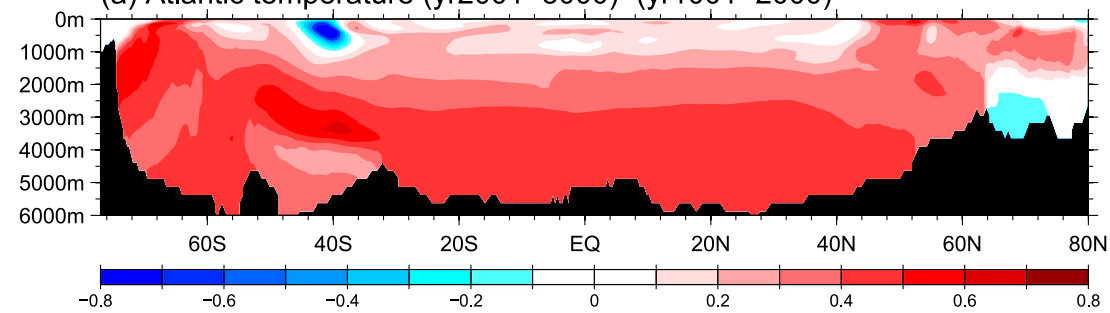

(b) Subsurface heat buildup in the Weddell Sea

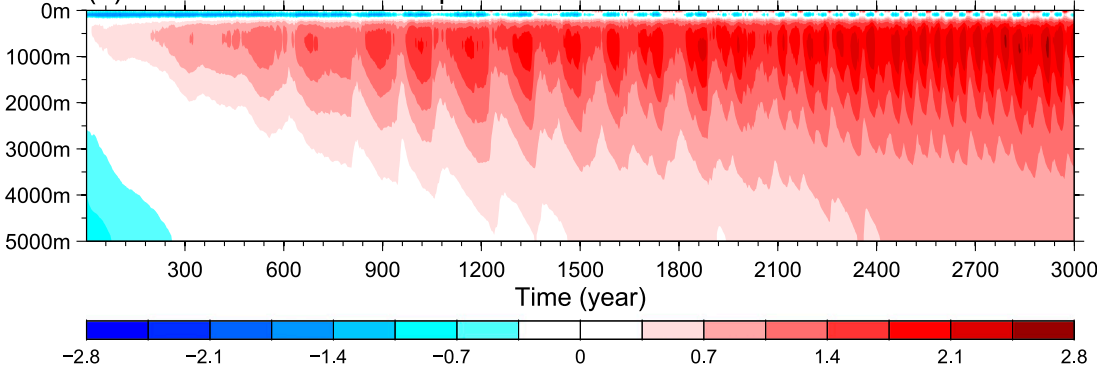

(c) Heat budget terms in the interior Weddell Sea

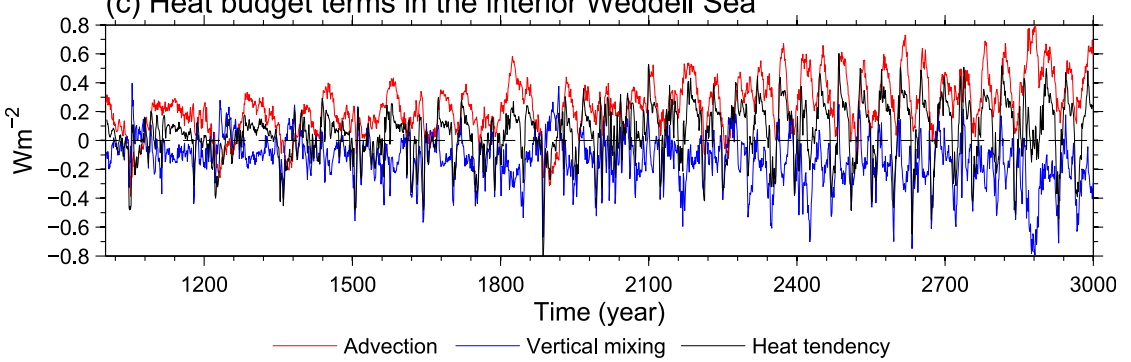

FIG. 14. (a) Atlantic zonal mean $\left(80^{\circ} \mathrm{W}-20^{\circ} \mathrm{E}\right)$ temperature difference $\left({ }^{\circ} \mathrm{C}\right)$ between the 2001st-3000th years and the 1001st-2000th years in the SPEAR_AM2 control run. (b) Time evolutions of ocean temperature $\left({ }^{\circ} \mathrm{C}\right)$ averaged over the Weddell Sea $\left(77^{\circ}-57^{\circ} \mathrm{S}, 60^{\circ} \mathrm{W}-20^{\circ} \mathrm{E}\right)$. (c) Time evolutions of heat budget terms $\left(\mathrm{W} \mathrm{m}^{-2}\right)$ at $1550 \mathrm{~m}$ averaged over the Weddell Sea.

level (Fig. 16d). Due to the short records over the Dronning Maud Land coast (Fig. 15h), the power spectrum is difficult to interpret on centennial time scales (Fig. 16h).

To investigate how the centennial variability evolves with time, we conduct wavelet analyses of these temperature reconstructions (Fig. 17). As shown in Fig. 17a, the pronounced centennial variability of pan-Antarctic temperature occurs mostly after $1000 \mathrm{CE}$. Before $1000 \mathrm{CE}$, the temperature period is much shorter and mainly on multidecadal time scales (Fig. 17a). This period shift coincides with the background temperature changes. As exhibited in Fig. 15, the temperature is much warmer during 1-1000 CE than 1001-1900 CE. In the CMIP5 models, we find a close intermodel relationship between the SO SST and the ocean stratification in the control simulations. Models with a stronger ocean stratification background tend to have a lower long-term mean SO SST and vice versa (not shown). The related physical process is that stronger (weaker) ocean stratification hampers (favors) convective warming from below, thereby leading to cooler (warmer) seawater in the surface as well as lower (higher) temperature in the adjacent Antarctic continent. If this hypothesis also works in the past climate, a warmer (colder) Antarctica will correspond to a weaker (stronger) ocean stratification background over the SO. This implies that the pronounced centennial variability after $1000 \mathrm{CE}$ has a possibility to be related to a stronger-than-normal ocean stratification background over the SO. This speculation seems to be consistent with our argument from the sea ice albedo perturbation and subsurface warming drift experiments in the above two sections. Further examination finds that these centennial variabilities are largely from the Victoria Land/Ross Sea and the Weddell coast regions (Figs. 17b,c) where the amplitude is almost doubled. The large contributions of these two regions are also obvious from the power spectrum in Figs. 16d and 16g. These centennial variabilities are robust throughout the past 1000 years over these two regions (Figs. 17b,c).

All results shown in sections 3 and 4 based on GFDL models mainly involve ocean variables. We also directly compare surface air temperature variability in models with that from paleoclimate reconstructions (Fig. 18). The SO deep convection oscillation has strong impacts on the surface air temperature over the adjacent continent (e.g., Zhang et al. 2017a). We can observe significant low-frequency variability in almost all Antarctic regions in models. In the SPEAR_LO control run, 
(a) Whole Antarctica temperature

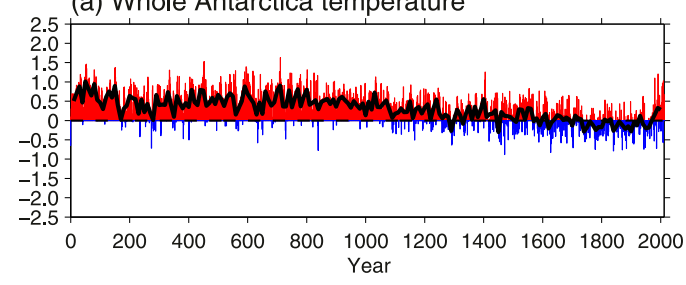

(c) Wilkes Land Coast temperature

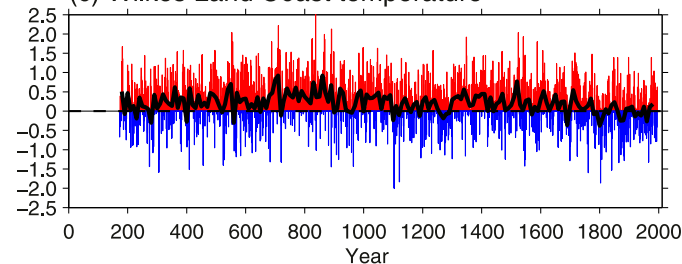

(e) West Antarctic Ice Sheet temperature

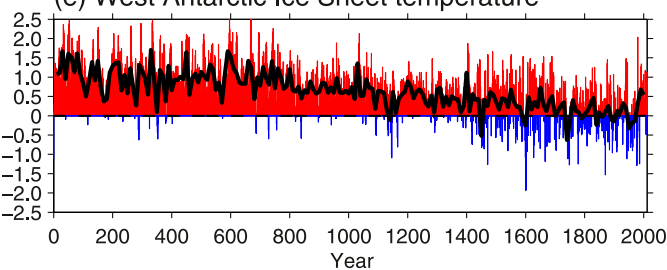

(g) Weddell Sea Coast temperature

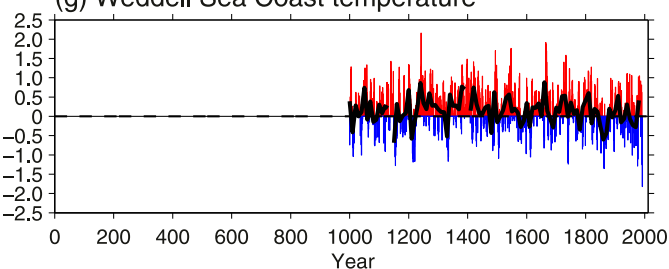

(b) Plateau temperature

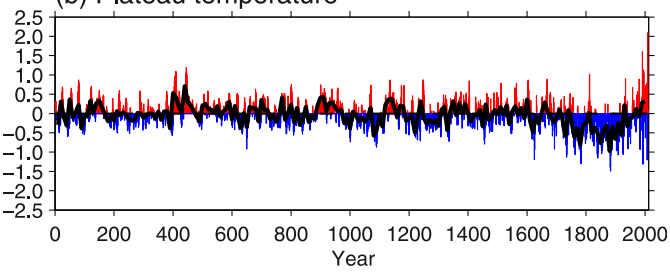

(d) Victoria Land. Ross Sea temperature
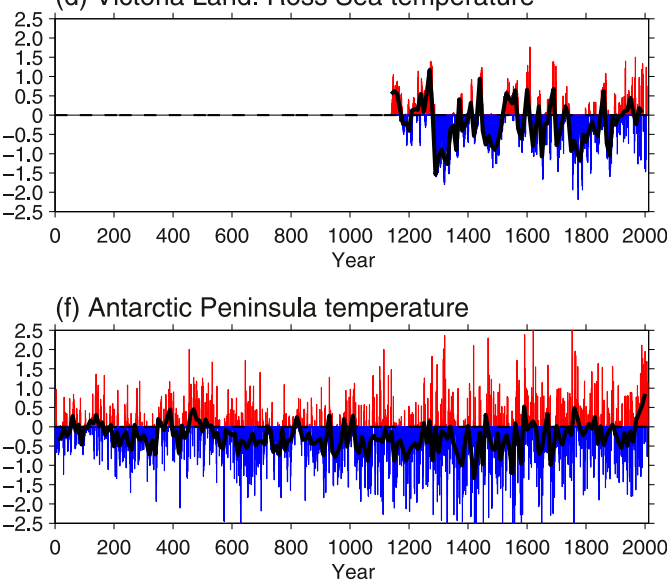

(h) Dronning Maud Land Coast temperature

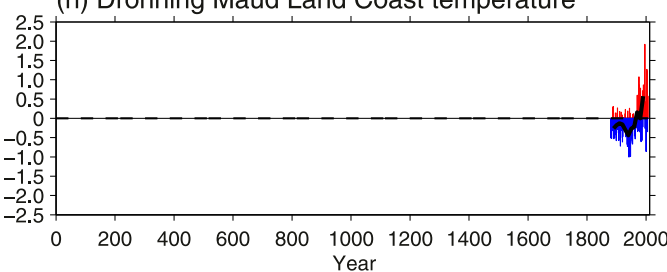

FIG. 15. Time evolutions of the regional temperature reconstructions $\left({ }^{\circ} \mathrm{C}\right.$; referenced to the $1900-90$ years $)$ using annual mean data for the past 2000 years over (a) all of Antarctica and the (b) plateau, (c) Wilkes Land coast, (d) Victoria Land/Ross Sea, (e) West Antarctic Ice Sheet, (f) Antarctic Peninsula, (g) Weddell Sea Coast, and (h) Dronning Maud Land coast regions from the CPS dataset. The bold black line overlapped in each subpanel is the low-frequency (10-yr mean data) temperature variability.

the strongest multidecadal air temperature variability $(\sim 80$ years) is in the Victoria Land Ross Sea where the deep convection occurs nearby (Fig. 18d). This strong low-frequency signal also spreads to the downstream West Antarctic Ice Sheet and Weddell Sea coast (Figs. 18e,g) and eventually affects all of Antarctica (Figs. 18b,c,f,h). In general, the closer to the location of deep convection, the stronger the signal. Since the plateau is in the interior of the Antarctic continent, the multidecadal variability is relatively weak over there. Similarly, the strongest centennial variability $(\sim 150$ years $)$ over land in the 1001st-2000th years of the SPEAR_AM2 model is in the Victoria Land/Ross Sea region and the Weddell Sea coast (Figs. 18d,g) because of the convection resonance between the Ross and Weddell Seas in this model during this period (Fig. 13c). This centennial variability is relatively weak over the plateau and the Wilkes Land Coast (Figs. 18b,c), which is again attributed to the geographical separation from the convective variability. Associated with the shift of convection position to the Weddell Sea in the 2001st-3000th years
(Fig. 13), the strongest multidecadal signal ( $\sim 40$ years) of surface air temperature moves to the Weddell Sea coast (Fig. 18g). The $\sim 40$-yr variability is also seen in other Antarctic regions; however, the magnitude is much smaller than that in the Weddell Sea coast (Fig. 18). Overall, the modeled lowfrequency variability in the Antarctica and its main places of occurrence seem to be realistic, which is also observed in paleoclimate reconstructions (Fig. 16).

Consistent with sections 3 and 4, the internal low-frequency air temperature variability over the Antarctica strongly depends on the SO mean state. As displayed in Fig. 18a, the stronger stratification mean state corresponds to an air temperature variability with longer period and larger amplitude and vice versa. This relationship is established in most subregions of the Antarctica (Figs. 18b-f,h). The Weddell Sea coast is an exception (Fig. 18g), since the internal variability during the 2001st-3000th years in the SPEAR_AM2 control run is strongly enhanced by an additional heat source from the NADW (Fig. 14). Thus, the 40-yr peak is extremely strong is this run, even though the ocean stratification mean state is the weakest 
(a) Whole Antarctica

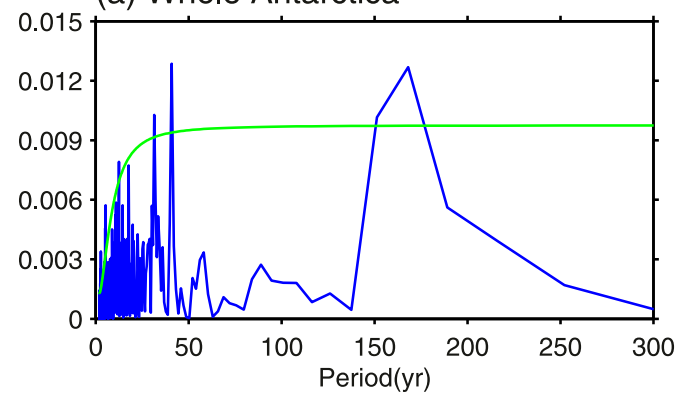

(c) Wilkes Land Coast

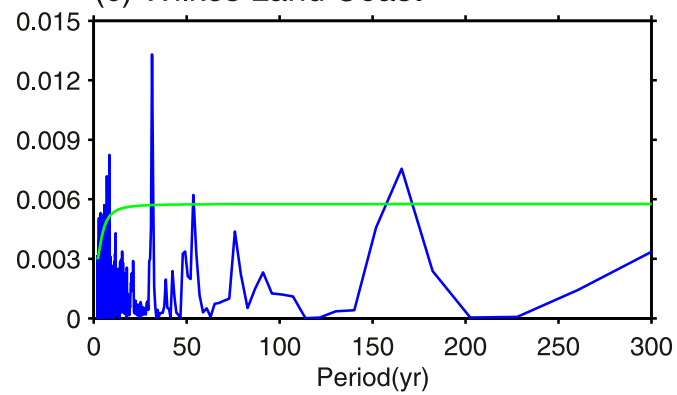

(e) West Antarctic Ice Sheet

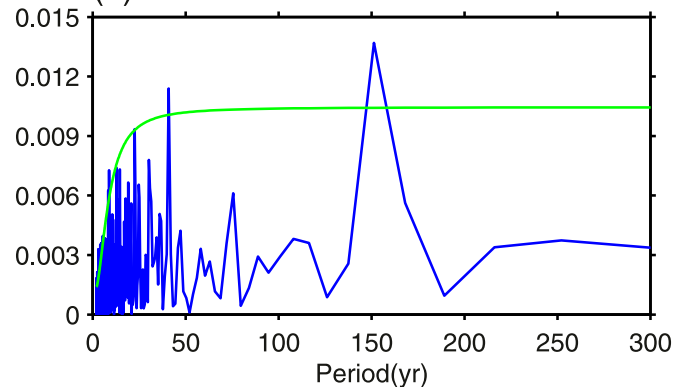

(g) Weddell Sea Coast

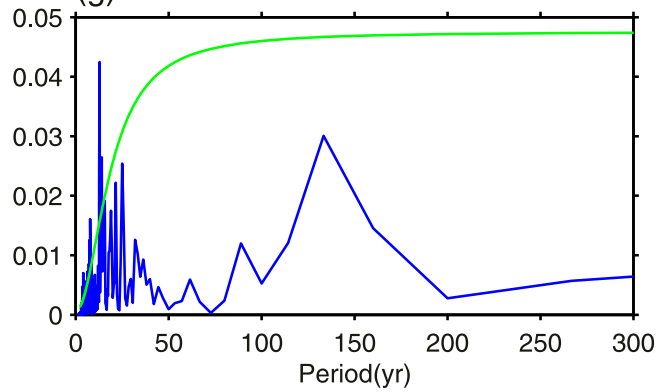

(b) Plateau

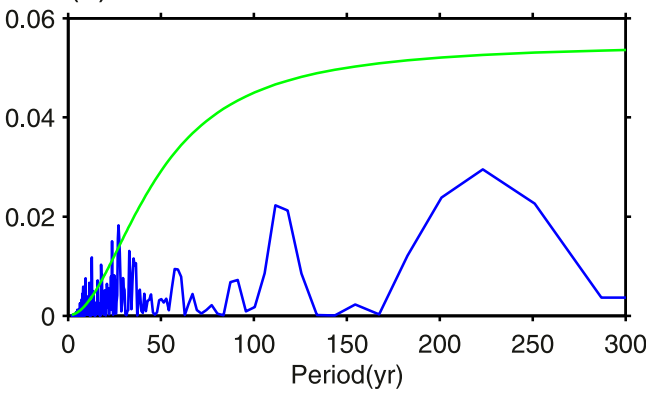

(d) Victoria Land. Ross Sea

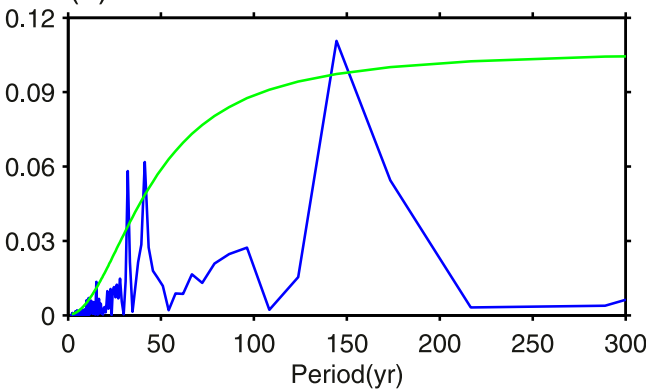

(f) Antarctic Peninsula

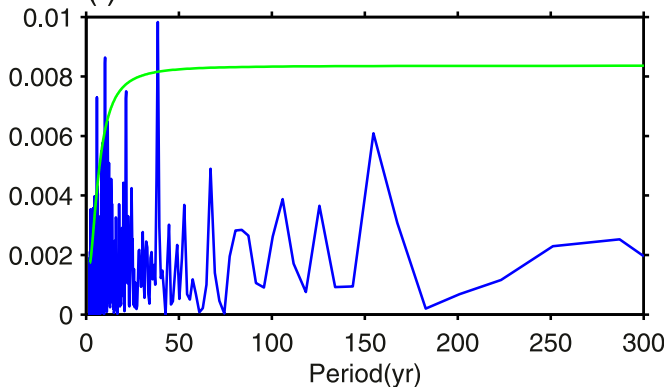

(h) Dronning Maud Land Coast

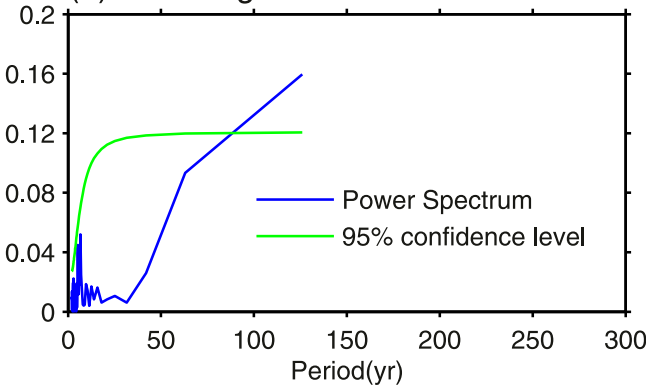

FIG. 16. Power spectrum of the normalized temperature reconstructions from Fig. 15. Blue lines denote the power spectrum of surface air temperature from the CPS dataset; green lines denote the $95 \%$ confidence level.

during this period (Fig. 18g). Compared to the low-frequency variability in paleoclimate reconstructions, it seems like the stronger stratification mean state in the SPEAR_AM2 model during the 1001st-2000th years with a significant $\sim 150$-yr period is more realistic than other runs (Fig. 16 vs Fig. 18). We also compare the ocean stratification during the weak convection regime in models with the ocean observations in 1979-2016 (not shown). The models' stratifications generally are weaker than that in observation, which may explain why there are no observed deep convection events during this period. However, the sparse observation over the SO, particularly in the subsurface ocean, provides large uncertainties regarding to this low-frequency convection variability. Moreover, models and observation may have different sensitivities of deep convection oscillation even with the same ocean stratification 
(a) Wavelet of the Whole Antarctica

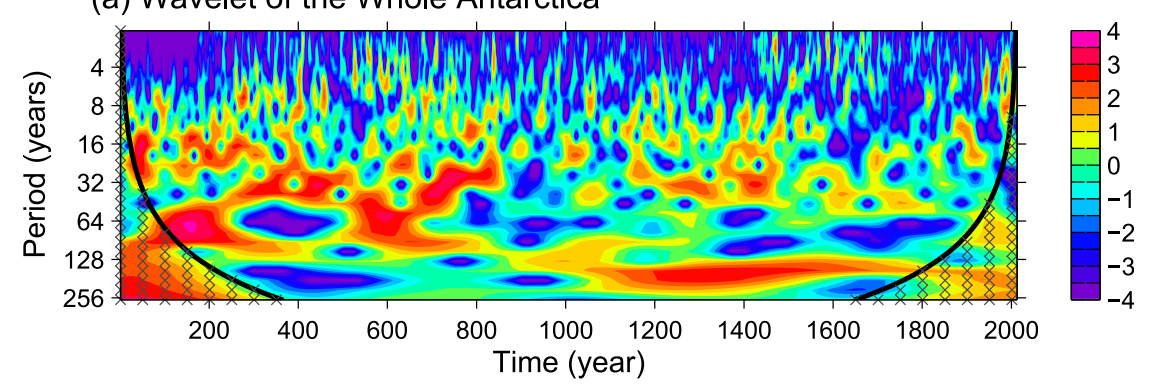

(b) Victoria Land. Ross Sea

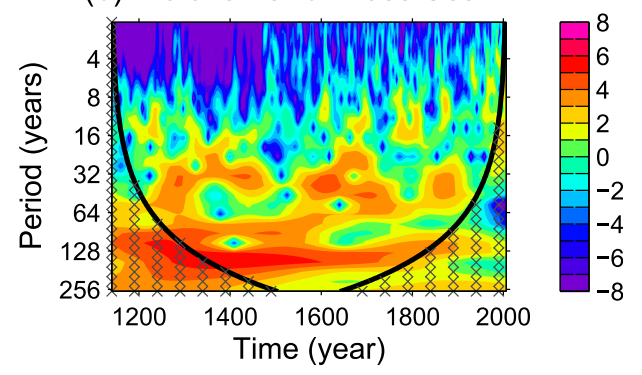

(c) Weddell Sea Coast

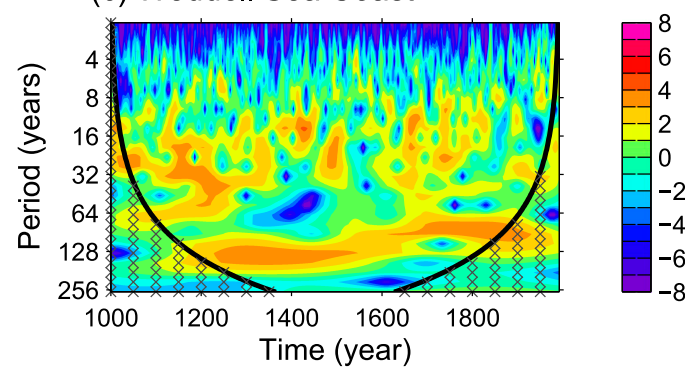

FIG. 17. Wavelet analysis of the annually surface air temperature reconstruction averaged over (a) all of Antarctica, (b) Victoria Land and the Ross Sea, and (c) the Weddell Sea coast from the CPS dataset. The crossing areas under the bold black curve denote these values are not significant at $95 \%$ confidence level.

background. We also note that the models underestimate the variability shorter than 40 years that is vigorous in paleoclimate reconstructions (Fig. 16 vs Fig. 18).

\section{Discussion and summary}

In the present paper, we investigate which processes influence SO internal low-frequency variability in terms of its period, amplitude, and location based on the GFDL SPEAR_LO and SPEAR_AM2 models. It is found that there is a strong linkage between the mean ocean stratification and the period and amplitude of SO internal variability. If the ocean stratification is too strong to allow the occurrence of deep convection, there will be no convection oscillations; this corresponds to what happens in the initial 500 years in the SPEAR_AM2 control simulation (Fig. 12). As the stratification weakens, there is a range of mean stratification values (a "window") for which the SO deep convection can oscillate with a significant low-frequency period. Within this oscillation window, a weaker ocean stratification mean state corresponds to a shorter period of internal convection variability and vice versa, no matter if the stratification perturbation is from ocean surface (section 3) or subsurface (section 4). This is because the convection trigger such as the subsurface heat buildup takes a shorter time to destabilize the ocean stratification and is more prone to induce the occurrence of deep convection under a weaker stratification mean state. Similarly, the surface freshwater either from advection or anomalous freshwater flux is easier to flip the convection phase from strong to weak convection regimes and vice versa. The same conclusion obtained from both models suggests that the convection period dependence on the ocean stratification mean state is not simply an artifact of one model. The conclusion here is also in agreement with the argument proposed by Reintges et al. (2017), who analyzed CMIP5 models. Zhang et al. (2017a,b) suggested that the SO SST predictability mainly arises from the deep convection memory. Here, we further show that the differences of the time scales of convection variability can lead to differences in the 
(a) Whole Antarctica

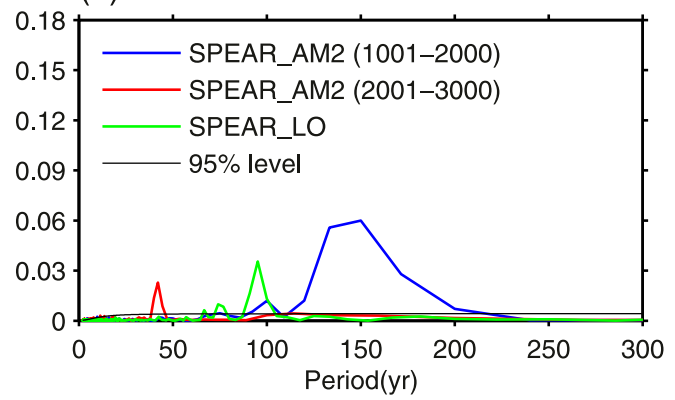

(c) Wilkes Land Coast

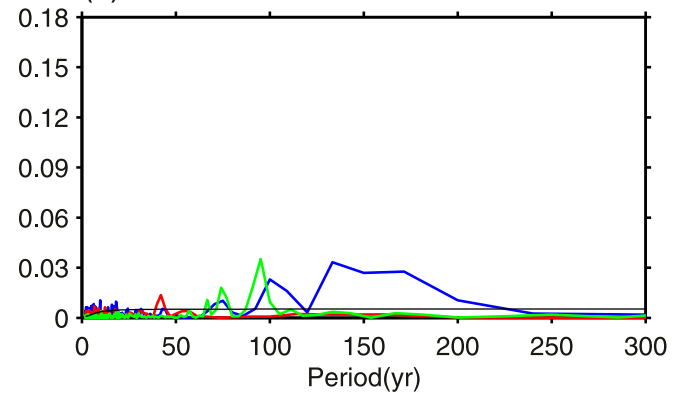

(e) West Antarctic Ice Sheet

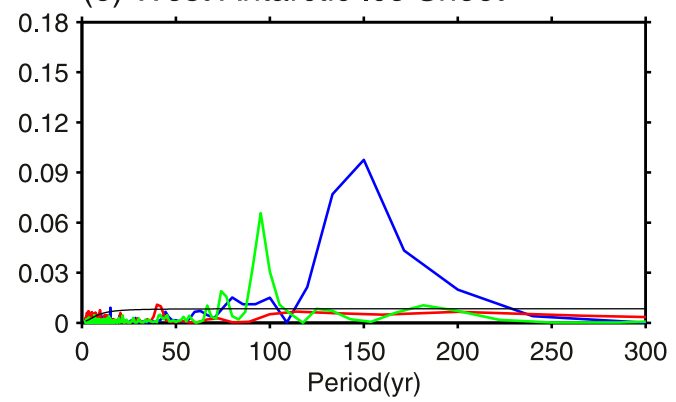

(g) Weddell Sea Coast

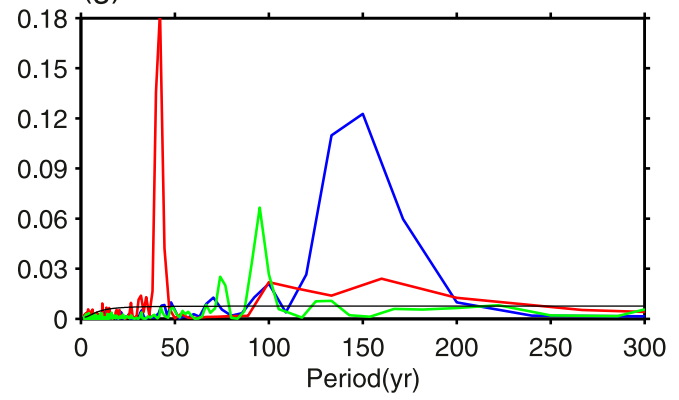

(b) Plateau

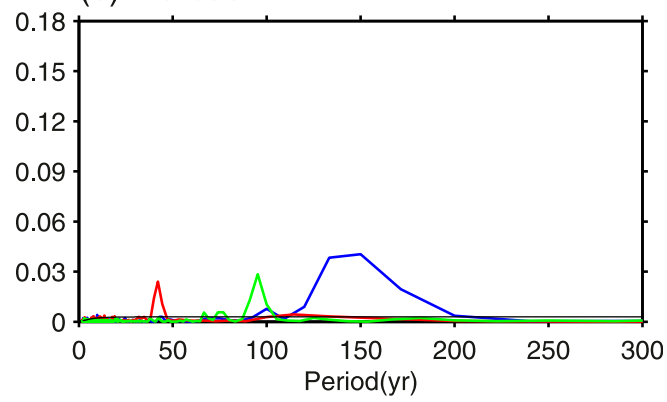

(d) Victoria Land. Ross Sea

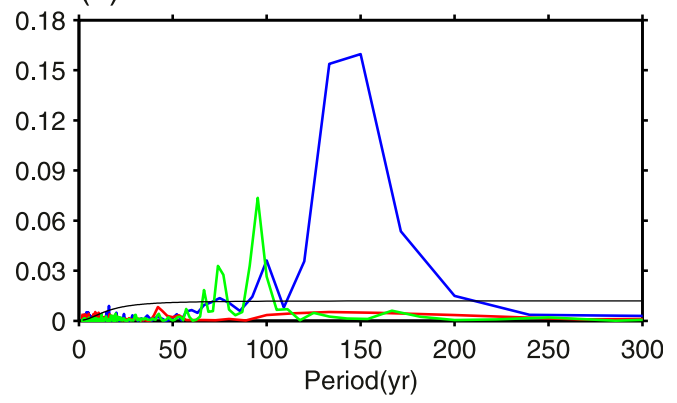

(f) Antarctic Peninsula

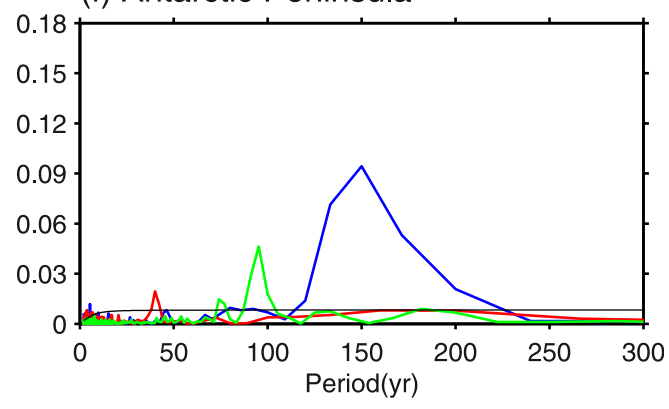

(h) Dronning Maud Land Coast

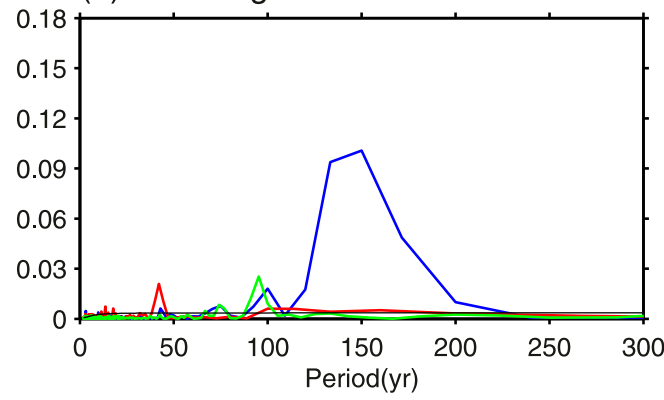

FIG. 18. As in Fig. 16, but for the surface air temperature spectrum in the SPEAR_LO control run and the 1001st2000th and 2001st-3000th years of the SPEAR_AM2 control simulation.

SO SST predictability. Figure 19 exhibits the predictability skills of the leading predictable component of SST over the SO derived from the statistical average predictability time (APT) method (e.g., DelSole and Tippet 2009; Zhang et al. 2017a). We can see that the shorter (longer) period of SO internal variability such as the Albedo ${ }^{+1.5}\left(\right.$ Albedo $^{-1.5}$ ) run corresponds to a lower (higher) predictability of the SO SST because of a shorter (longer) ocean persistence.
The amplitude of SO deep convection variability, however, is largely determined by the magnitude of subsurface heat reservoir established during the weak convection regime. The larger the subsurface heat reservoir, the larger amplitude the SO internal deep convection variability. The magnitude of subsurface heat reservoir represents how much energy the subsurface ocean has saved during the weak convection regimes. When convection occurs, this subsurface heat depletes, 


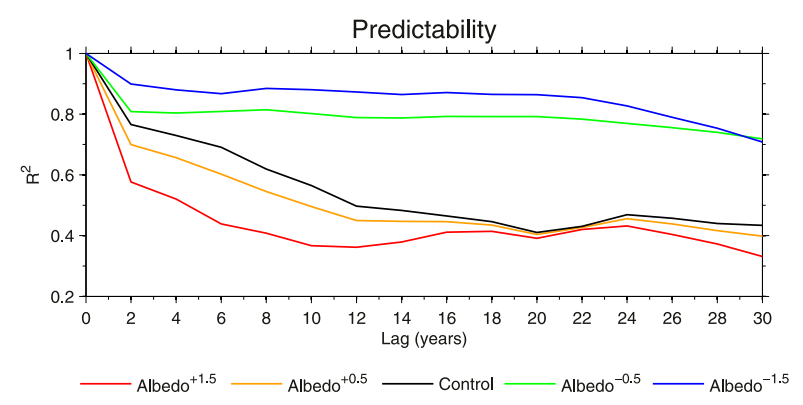

FIG. 19. Shown are the squared multiple correlation coefficients $R^{2}$ of the leading predictable SST mode over the Southern Ocean in the SPEAR_LO Albedo ${ }^{+1.5}$, Albedo $^{+0.5}$, Control, Albedo ${ }^{-0.5}$, and Albedo $^{-1.5}$ experiments.

and eventually releases to the atmosphere. Heat budget analysis reveals that the subsurface heat buildup is mainly balanced between advection that replenishes the heat reservoir and vertical mixing that depletes it. The weak ocean stratification mean state is largely associated with enhanced gravitational instability and enhanced vertical mixing and vice versa. If the advection changes are small or negligible, the weak ocean stratification background will correspond to a small subsurface heat buildup since the enhanced vertical mixing erodes the subsurface heat reservoir. This situation is applicable to our sea ice albedo perturbation experiments (section 3), in which the weaker (stronger) ocean stratification corresponds to a smaller (larger) amplitude of deep convection variability (Figs. 7-10). This situation also occurs in Dufour et al. (2017), who found that the GFDL CM2.6 model has a stronger ocean stratification than the CM2.5 model due to the restratifying effect of eddies; thus, the CM2.6 has a larger subsurface heat reservoir that favors the occurrence of Weddell Sea Polynya. However, if the advection changes are large enough to overwhelm the contribution from vertical mixing, the above relationship will not establish. In the 2001st-3000th years of the SPEAR_AM2 control simulation (section 4), the warming drift penetrates to the NADW and LCDW, which provide a continuous heat source for the SO subsurface heat reservoir. This additional heat is advected into the subsurface Weddell Sea by the Weddell Gyre. This anomalous warm temperature advection overwhelms the cooling effect of vertical mixing due to the weakening of stratification. Thus, the subsurface heat reservoir and therefore the amplitude of deep convection variability are quite large in the last 1000 years of the SPEAR_AM2 run, although the ocean stratification weakens over the Weddell Sea during this period. It is worth noting that the results we show here are based on low-resolution models. It is important to assess the robustness of these results at some time in the future using a high-resolution model that can better resolve ocean eddies.

The distinct locations of open ocean deep convection in the SPEAR_AM2 control simulation during different periods provide us some insights into the CMIP5 models. We can see even in one model that the deep convection locations can vary under different mean states (Figs. 12 and 13). In the initial 500 years, the model does not have an obvious deep convection oscillation because of strong ocean stratification. Similar situations occur in some CMIP5 models such as the CCSM4 model in which deep convection fluctuations are not apparent. During the 1000th-2000th year of the SPEAR_AM2 model control run, the ocean stratification weakens and favors occurrences of open ocean deep convection. The deep convection events appear in both the Ross and Weddell Seas and these two basins tend to resonate. During the 2001st-3000th years of the model run, the surface freshwater suppresses the convection variability over the Ross Sea, while the continuous heat from the NADW and the LCDW further strengthens the open ocean deep convection over the Weddell Sea. Thus, the open ocean deep convection mainly occurs over the Weddell Sea during this stage. These phenomena suggest that multiple processes are at work in each basin. Both the surface and subsurface conditions are crucial for the deep convection variability. In different basins, the mean ocean circulation, topography, small-scale ocean eddy activities, ocean mixing, and adjacent continent and local atmosphere conditions have sharp differences. These factors also vary in different models because of differences in model resolution and parameterizations and vary in different periods even within one model. In each model and each basin, the comprehensive integration of these factors in each period determines whether the mean state favors the convection occurrences or not. Moreover, different models may have different sensitivities, which means the models can have different responses even with the same forcing. Thus, the CMIP5 models are very diverse regarding the SO deep convection locations and variability.

The internal multidecadal to centennial variability over the SO simulated by models have yet to be disproven in the real world. The temperature reconstructions retrieved from ice core records show pronounced centennial variabilities in most regions over the Antarctic continent (Figs. 15-17). In the Ross and Weddell coasts, these centennial variabilities are robust throughout the past 1000 years (Fig. 17). Given such long-time scales, we think this low-frequency variability has a large possibility to be related to the ocean that has a long memory. However, it is still not clear what ocean processes are related to these low-frequency variabilities in reality, given the sparse observation in the subsurface ocean. The candidate open ocean deep convection was observed only once over the Weddell Sea by the satellite: 1974-76 (Gordon 1978). The recent Weddell Polynya in 2016-17 is more like to have been induced by concurrent upper ocean preconditioning and severe storms (Campbell et al. 2019). It is unclear whether the open ocean deep convection will happen or not in future. After all, the anthropogenic warming-induced freshwater fluxes tend to hamper the open ocean deep convection (e.g., de Lavergne et al. 2014; Bronselaer et al. 2018). This calls for in situ long time ocean observations in the SO, particularly in the subsurface ocean. Understanding the SO low-frequency variability will help us to better predict future changes in the polar regions that have far-reaching impacts on global climate, the carbon cycle, and ecosystems.

Acknowledgments. We are grateful to John Dunne and John Krasting for their constructive comments on an early version of the paper, who provided extremely insightful and valuable 
feedback and suggestions. We also acknowledge three anonymous external reviewers for their excellent comments and suggestions. The work of T. Delworth and X. Yang is supported as a base activity of NOAA's Geophysical Fluid Dynamics Laboratory. L. Zhang, W. Cooke, and M. Bushuk are supported through UCAR under block funding from NOAA/GFDL. H. Goosse, research director within the F.R.S.FNRS, is supported by the Belgian Research Action through Interdisciplinary Networks (BRAINbe) from Belgian Science Policy Office. Y. Morioka is supported as a base activity of JAMSTEC's Application Laboratory and funded by JSPS KAKENHI Grant 19K14800.

\section{REFERENCES}

Adcroft, A., and Coauthors, 2019: The GFDL global ocean and sea ice model OM4.0: Model description and simulation features. J. Adv. Model. Earth Syst., 11, 3167-3211, https://doi.org/ 10.1029/2019MS001726.

Anderson, J. L., and Coauthors, 2004: The new GFDL global atmosphere and land model AM2-LM2: Evaluation with prescribed SST simulations. J. Climate, 17, 4641-4673, https:// doi.org/10.1175/JCLI-3223.1.

Bitz, C. M., P. R. Gent, R. A. Woodgate, M. M. Holland, and R. Lindsay, 2006: The influence of sea ice on ocean heat uptake in response to increasing $\mathrm{CO}_{2}$. J. Climate, 19, 2437-2450, https://doi.org/10.1175/JCLI3756.1.

Briegleb, B. P., 1992: Delta-Eddington approximation for solar radiation in the NCAR Community Climate Model. J. Geophys. Res., 97, 7603-7612, https://doi.org/10.1029/92JD00291.

Bronselaer, B., M. Winton, S. M. Griffies, W. J. Hurlin, K. B. Rodgers, O. V. Sergienko, R. J. Stouffer, and J. L. Russell, 2018: Change in future climate due to Antarctic meltwater. Nature, 564, 53-58, https://doi.org/10.1038/s41586-018-0712-z.

Cabré, A., I. Marinov, and A. Gnanadesikan, 2017: Global atmospheric teleconnections and multidecadal climate oscillations driven by Southern Ocean convection. J. Climate, 30, 81078126, https://doi.org/10.1175/JCLI-D-16-0741.1.

Campbell, E. C., E. A. Wilson, G. W. K. Moore, S. C. Riser, C. E. Brayton, M. R. Mazloff, and L. D. Talley, 2019: Antarctic offshore polynyas linked to Southern Hemisphere climate anomalies. Nature, 570, 319-325, https://doi.org/10.1038/s41586-019-1294-0.

Cook, E. R., B. M. Buckley, R. D. D'Arrigo, and M. J. Peterson, 2000: Warm-season temperatures since $1600 \mathrm{BC}$ reconstructed from Tasmanian tree rings and their relationship to large-scale sea surface temperature anomalies. Climate Dyn., 16, 79-91, https://doi.org/10.1007/s003820050006.

de Lavergne, C., J. B. Palter, E. D. Galbraith, R. Bernardello, and I. Marinov, 2014: Cessation of deep convection in the open Southern Ocean under anthropogenic climate change. Nat. Climate Change, 4, 278-282, https://doi.org/10.1038/nclimate2132.

DelSole, T., and M. Tippet, 2009: Average predictability time. Part I: Theory. J. Atmos. Sci., 66, 1172-1187, https://doi.org/ 10.1175/2008JAS2868.1.

Delworth, T. L., and Coauthors, 2012: Simulated climate and climate change in the GFDL CM2.5 high-resolution coupled climate model. J. Climate, 25, 2755-2781, https://doi.org/ 10.1175/JCLI-D-11-00316.1.

— , and Coauthors, 2020: SPEAR-the next generation GFDL modeling system for seasonal to multidecadal prediction and projection. J. Adv. Model. Earth Syst., 12, e2019MS001895, https://doi.org/10.1029/2019MS001895.
Dufour, C. O., A. K. Morrison, S. M. Griffies, I. Frenger, H. Zanowski, and M. Winton, 2017: Preconditioning of the Weddell Sea polynya by the ocean mesoscale and dense water overflows. J. Climate, $\mathbf{3 0}$, 7719-7737, https://doi.org/10.1175/JCLI-D-16-0586.1.

Ganachaud, A., and C. Wunsch, 2001: Improved estimates of global ocean circulation, heat transport and mixing from hydrographic data. Nature, 408, 453-457, https://doi.org/10.1038/ 35044048.

Gordon, A. L., 1978: Deep Antarctic convection west of Maud Rise. J. Phys. Oceanogr., 8, 600-612, https://doi.org/10.1175/ 1520-0485(1978)008<0600:DACWOM > 2.0.CO;2.

- M. Visbeck, and J. C. Cosimo, 2007: A possible link between the Weddell Polynya and the southern annular mode. J. Climate, 20, 2558-2571, https://doi.org/10.1175/JCLI4046.1.

Heuzé, C., K. J. Heywood, D. P. Stevens, and J. K. Ridley, 2013: Southern Ocean bottom water characteristics in CMIP5 models. Geophys. Res. Lett., 40, 1409-1414, https://doi.org/ 10.1002/grl.50287.

Kjellsson, J., and Coauthors, 2015: Model sensitivity of the Weddell and Ross Seas, Antarctica, to vertical mixing and freshwater forcing. Ocean Modell., 94, 141-152, https://doi.org/10.1016/ j.ocemod.2015.08.003.

Latif, M., T. Martin, and W. Park, 2013: Southern Ocean sector centennial climate variability and recent decadal trends. J. Climate, 26, 7767-7782, https://doi.org/10.1175/JCLI-D-1200281.1.

Le Quesne, C., C. Acuña, J. A. Boninsegna, A. Rivera, and J. Barichivich, 2009: Long-term glacier variations in the central Andes of Argentina and Chile, inferred from historical records and tree-ring reconstructed precipitation. Palaeogeogr. Palaeoclimatol. Palaeoecol., 281, 334-344, https://doi.org/10.1016/ j.palaeo.2008.01.039.

Lique, C., and M. D. Thomas, 2018: Latitudinal shift of the Atlantic meridional overturning circulation source regions under a warming climate. Nat. Climate Change, 8, 1013-1020, https:// doi.org/10.1038/s41558-018-0316-5.

Liu, W., A. Fedorov, and F. Sévellec, 2019: The mechanisms of the Atlantic meridional overturning circulation slowdown induced by Arctic sea ice decline. J. Climate, 32, 977-996, https:// doi.org/10.1175/JCLI-D-18-0231.1.

Marsland, S., and J.-O. Wolff, 2001: On the sensitivity of Southern Ocean sea ice to the surface freshwater flux: A model study. J. Geophys. Res., 106, 2723-2741, https://doi.org/10.1029/ 2000JC900086.

Martin, T., W. Park, and M. Latif, 2013: Multi-centennial variability controlled by Southern Ocean convection in the Kiel Climate Model. Climate Dyn., 40, 2005-2022, https://doi.org/ 10.1007/s00382-012-1586-7.

Martinson, D. G., P. D. Killworth, and A. L. Gordon, 1981: A convective model for the Weddell polynya. J. Phys. Oceanogr., 11, 466-488, https://doi.org/10.1175/1520-0485(1981)011<0466:ACMFTW>2.0. $\mathrm{CO} ; 2$.

McGregor, H. V., and Coauthors, 2015: Robust global ocean cooling trend for the past two millennia. Nat. Geosci., 8, 671677, https://doi.org/10.1038/ngeo2510.

Motoi, T., N. Oho, and M. Wakatsuchi, 1987: A mechanism for the formation of the Weddell Polynya in 1974. J. Phys. Oceanogr., 17, 22412247, https://doi.org/10.1175/1520-0485(1987)017<2241:AMFTFO> 2.0.CO;2.

Nicolas, J. P., and D. H. Bromwich, 2014: New reconstruction of Antarctic near-surface temperatures: Multidecadal trends and reliability of global reanalyses. J. Climate, 27, 8070-8093, https://doi.org/10.1175/JCLI-D-13-00733.1. 
Pierce, D., T. P. Barnett, and U. Mikolajewicz, 1995: Competing roles of heat and freshwater flux in forcing thermohaline oscillations. J. Phys. Oceanogr., 25, 2046-2064, https://doi.org/ 10.1175/1520-0485(1995)025<2046:CROHAF $>2.0$. CO;2.

Reintges, A., T. Martin, M. Latif, and W. Park, 2017: Physical controls of Southern Ocean deep-convection variability in CMIP5 models and the Kiel Climate Model. Geophys. Res. Lett., 44, 6951-6958, https://doi.org/10.1002/2017GL074087.

Seviour, W. J. M., A. Gnanadesikan, and D. W. Waugh, 2016: The transient response of the Southern Ocean to stratospheric ozone depletion. J. Climate, 29, 7383-7396, https://doi.org/ 10.1175/JCLI-D-16-0198.1.

- - , and M. A. Pradal, 2017: Transient response of the Southern Ocean to changing ozone: Regional responses and physical mechanisms. J. Climate, 30, 2463-2480, https://doi.org/ 10.1175/JCLI-D-16-0474.1.

Stenni, B., and Coauthors, 2017: Antarctic climate variability on regional and continental scales over the last 2000 years. Climate Past, 13, 1609-1634, https://doi.org/10.5194/cp-131609-2017.

Stössel, A., D. Notz, F. A. Haumann, H. Haak, J. Jungclaus, and U. Mikolajewicz, 2015: Controlling high-latitude Southern Ocean convection in climate models. Ocean Modell., 86, 5875, https://doi.org/10.1016/j.ocemod.2014.11.008.

Thomas, E. R., and Coauthors, 2019: Antarctic sea ice proxies from marine and ice core archives suitable for reconstructing sea ice over the past 2000 years. Geosciences, 9, 506, https://doi.org/ 10.3390/geosciences9120506.

Welander, P., 1982: A simple heat-salt oscillator. Dyn. Atmos. Oceans, 6, 233-242, https://doi.org/10.1016/0377-0265(82)90030-6.
Xie, S.-P., and K. Saito, 2001: Formation and variability of a northerly ITCZ in a hybrid coupled AGCM: Continental forcing and ocean-atmospheric feedback. J. Climate, 14, 1262-1276, https://doi.org/10.1175/1520-0442(2001)014<1262: FAVOAN $>2.0 . \mathrm{CO} ; 2$.

Zanowski, H., R. Hallberg, and J. L. Sarmiento, 2015: Abyssal ocean warming and salinification after Weddell polynyas in the GFDL CM2G coupled climate model. J. Phys. Oceanogr., 45, 2755-2772, https://doi.org/10.1175/JPO-D-15-0109.1.

Zhang, L., and T. L. Delworth, 2016: Impact of the Antarctic bottom water formation on the Weddell Gyre and its northward propagation characteristics in GFDL model. J. Geophys. Res. Oceans, 121, 5825-5846, https://doi.org/10.1002/2016 JC011790.

$\longrightarrow, \ldots$, and L. Jia, 2017a: Diagnosis of decadal predictability of Southern Ocean sea surface temperature in the GFDL CM2.1 model. J. Climate, 30, 6309-6328, https://doi.org/10.1175/JCLID-16-0537.1.

,-- X. Yang, R. G. Gudgel, L. Jia, G. A. Vecchi, and F. Zeng, 2017b: Estimating decadal predictability for the Southern Ocean using the GFDL CM2.1 model. J. Climate, 30, 5187-5203, https://doi.org/10.1175/JCLI-D-16-0840.1.

,,-- W. Cooke, and X. Yang, 2019: Natural variability of Southern Ocean convection as a driver of observed climate trends. Nat. Climate Change, 9, 59-65, https://doi.org/10.1038/ s41558-018-0350-3.

Zhao, M., and Coauthors, 2018: The GFDL global atmosphere and land model AM4.0/LM4.0: 2. Model description, sensitivity studies, and tuning strategies. J. Adv. Model. Earth Syst., 10, 735-769, https://doi.org/10.1002/2017MS001209. 